\title{
Can competing diversity indices inform us about why ethnic diversity erodes social cohesion? A test of five diversity indices in Germany
}

\author{
Merlin Schaeffer \\ University of Cologne \\ Please cite as: Schaeffer, Merlin. 2013. "Can Competing Diversity Indices Inform Us \\ About Why Ethnic Diversity Erodes Social Cohesion? A Test of Five Diversity Indices in \\ Germany." Social Science Research 42(3):755-74
}

\begin{abstract}
An ever-growing number of studies investigates the relation between ethnic diversity and social cohesion, but these studies have produced mixed results. In cross-national research, some scholars have recently started to investigate more refined and informative indices of ethnic diversity than the commonly used Hirschman-Herfindahl Index. These refined indices allow to test competing theoretical explanations of why ethnic diversity is associated with declines in social cohesion. This study assesses the applicability of this approach for sub-national analyses. Generally, the results confirm a negative association between social cohesion and ethnic diversity. However, the competing indices are empirically indistinguishable and thus insufficient to test different theories against one another. Follow-up simulations suggest the general conclusion that the competing indices are meaningful operationalizations only if a sample includes: (1) contextual units with small and contextual units with large minority shares, as well as (2) contextual units with diverse and contextual units with polarized ethnic compositions. The results are thus instructive to all researchers who wish to apply different diversity indices and thereby test competing theories.
\end{abstract}

Keywords: ethnic diversity, social cohesion, social capital, immigration,

Email address: merlin.schaeffer@uni-koeln.de (Merlin Schaeffer)

Preprint submitted to Social Science Research 42(3):755-74 
diversity indices, entropy, Germany

\section{1. Introduction}

Following the seminal studies of Alesina et al. (1999) and Putnam (2007), there has been a growing debate on the supposedly negative relation between ethnic diversity and social cohesion over the last years. Particularly European researchers have shown an interest, given the implications of such an association for European countries that have experienced growing diversification because of immigration. Is there a threat to the high levels of trust (e.g. Gundelach and Traunmüller, forthcoming), civic engagement (e.g. Vermeulen et al., 2011) and support for redistribution (e.g. Stichnoth, 2012) that characterize European countries?

The literature on ethnic diversity and social cohesion provides a rich set of empirical findings, but the overall picture is inconclusive (Portes and Vickstrom, 2011). The two existing quantitative reviews unearth patterns such as that the "main evidence for negative diversity effects is found for intra-neighborhood social cohesion" (van der Meer and Tolsma, 2011, p. 30) or that "North American studies tend to provide more confirmatory results, which cannot be said about studies from developing countries or cross-national comparisons and probably neither for Europe" (Schaeffer, 2012, p. 44). Against this background arises the necessity to study why ethnic diversity should result in lower levels of social cohesion. Only if we understand what it is about ethnic diversity that undermines social cohesion, we can postulate hypotheses about the conditions under which we should expect ethnic diversity to reduce social cohesion and under which conditions we should not. If for example ethnic diversity was about communication and coordination problems, as Habyarimana et al. (2007) propose, we would not expect a strong ethnic diversity effect in countries where immigrants tend to speak the native language, such as France.

Even though a number of plausible theoretical explanations have been proposed, most studies provide no evidence for the supremacy of one explanation 
over others. This situation makes it hard to judge the overall inconclusive findings. Attempting to fill this gap, some researchers have recently started to investigate more refined and informative measures of ethnic diversity than the commonly used Hirschman-Herfindahl Index. Desmet et al. (2009) for example test a linguistically weighted index of ethnic diversity, and Baldwin and Huber (2010) an index of economic inequality between ethnic groups. Such studies yield suggestive evidence on the relevance of certain theoretical explanations, be they concerned with communication problems or unequal resource allocation as in these examples. Unfortunately, the few existing, pioneering studies all engage in cross-national comparisons, while the earlier discussed research on the effects of ethnic diversity has generated mixed results particularly on the sub-national level of European countries (e.g. Savelkoul et al., 2011; Gijsberts et al., 2011; Tolsma et al., 2009).

This paper reports about the merits of comparing competing diversity indicators in sub-national analyses, i.e. the aim is to investigate whether different theories on why ethnic diversity should result in lower levels of social cohesion can be tested against one another, by comparing the explanatory power of rival diversity indices. As such, the paper tries to answer both substantial as well as methodological questions. I make use of the German sub-set of the Ethnic Diversity and Collective Action Survey (Schaeffer et al., 2011) with its roughly 7,500 respondents, who live in one of 55 theoretically and randomly sampled German cities and regions. In particular, I compare the explanatory power of the following indices: First, the common Herfindhal-Hirschman index of ethnic diversity and an ethnic polarization index are taken as operationalizations of cognitive biases. Second, a culturally weighted ethnic diversity index and an index of ethnic group-based income inequality are treated as indicators of asymmetrically distributed preferences. Finally, a measure of average migrant host-country language skills is used as an indicator of coordination problems. As dependent variables, I investigate trust in neighbours and collective efficacy as indicators of neighbourhood social cohesion.

However, while I find negative associations between the indicators of social 
cohesion and ethnic diversity, the competing indices are empirically indistinguishable and thus insufficient to test different theories against one another. By conducting follow-up simulations on these results, I can identify the general conditions under which competing diversity indices become meaningfully different from another: If the majority share is too large in even the most diverse cities and regions, and if the sample does not cover contextual units with diverse and contextual units with polarized ethnic compositions, the competing indices are indistinguishable even from the mere percentage of minorities. Substantially this implies that much of the (European) research on ethnic diversity and social cohesion might actually be about majority responses to minority concentration and disclose little about diversity effects per se. The conducted follow-up simulations indicate, however, under which conditions the various indices do indeed become telling and are thus instructive to all researchers who wish to apply different diversity indices and thereby test competing theories.

\section{Theoretical background}

The central aim of this paper is to test different theories on why ethnic diversity should result in lower levels of social cohesion, by comparing the explanatory power of competing diversity indices. Following Chan et al. (2006), but focusing on neighbourhoods rather than whole societies, I understand the concept of social cohesion to encompass feelings of shared commonalities, trust, reciprocity and solidarity that generate a social environment in which people produce and share public goods and undertake collective endeavours. Testing theories on ethnic diversity and social cohesion by comparing the explanatory power of competing diversity indices, requires a discussion of different theories, but more importantly it requires linking these theories to different diversity indices. ${ }^{1}$ Which index should be regarded as operationalization of which theory? The literature discusses roughly five explanations of why ethnic diversity should

${ }^{1} \mathrm{~A}$ thorough discussion of and introduction to diversity indices in general is given by Rao (1982) and Greenberg (1956). 
drive down levels of social cohesion. Two of these explanations focus on cognitive biases that are associated with mere categorical differences of "us" versus "them". Particularly sociologists and many political scientists see these cognitive biases as being rooted in feelings of group threat, whereas economists and social psychologists rather refer to in-group favouritism. Two other explanations take actual cultural differences into account. Probably because of Deutsch's (1966) heritage, who emphasized the importance of shared language for nation states, it seems to be particularly political scientists who are among the few who see coordination problems as explaining lower levels of social cohesion in mixed contexts. Economists on the other hand frequently discuss asymmetrically distributed preferences and the inability to agree on shared goals as potential explanation. Much less attention has been paid to explaining negative diversity effects by ethnically clustered networks that result in lower levels of social control (e.g. Miguel and Gugerty, 2005). This paper is no exception to this trend, because constructing an index of network density from data of randomly sampled individuals is not straightforward (Wasserman and Faust, 1994). Table 1 gives an overview of the explanations and the linked diversity indices (for further explanations see below). In the following, I will discuss the first four theoretical explanations in more detail and link them to a set of five diversity indices.

Table 1: Theoretical explanations and associated diversity indices

\begin{tabular}{lll}
\hline Type & Theoretical explanation & Index \\
\hline \multirow{2}{*}{ Ethno-categorical diversity } & In-group favouritism & HHI \\
& Group threat & EP \\
\hline \multirow{2}{*}{ Ethno-cultural diversity } & Asymmetric distribution of preferences & CED \& EGI \\
& Coordination problems & LSU \\
\hline Ethno-structural diversity & Social control & Not investigated \\
\hline
\end{tabular}

\subsection{Ethno-categorical diversity}

Most studies that investigate ethnic diversity employ indices that rely on publicly available data of a population's national, racial or ethnic composition. I propose to call these indices indicators of ethno-categorical diversity, because 
they reflect a population's diversity as measured by statistically available categories that ignore any cultural or economic distances between those categories.

\subsubsection{In-group favouritism}

Among others, Alesina et al. (1999) and Alesina and La Ferrara (2002) refer to social identity theory (Brown, 2000; Tajfel et al., 1971) and argue that since people favour others who are alike, they trust people of other descent less and avert cooperation when out-group members benefit as well. If the statistically available categories reflect the ethnic boundaries people have in mind, and if in-group favouritism is the main cause of the ethnic diversity effect, we should find that the commonly used Hirschman-Herfindahl Index (HHI) is the most adequate predictor of social cohesion (H1). The reason is that for in-group favouritism it is only the question whether someone belongs to an in-group or out-group that matters and the share of minorities fulfils this criterion only for the majority population. Results based on the percentage of ethnic minorities as diversity proxy actually measure majority responses to minority concentration rather than diversity effects per se. In most studies, the classical HirschmanHerfindahl Index (Hirschman, 1964) is subtracted from unity:

$$
\mathrm{HHI}=1-\sum_{i=1}^{k} s_{i}^{2}
$$

where $s_{i}$ denotes the share of ethnic category $i$ and $k$ the number of categories. This index can be interpreted as the likelihood that two randomly drawn individuals do not share membership in the same ethnic category. It varies between a minimum of 0 for contexts with only one category and a maximum of 1 , which is reached when the population is divided into an infinitive amount of categories.

\subsubsection{Group threat}

Another approach that deals with cognitive biases cites competition (e.g. Olzak, 1992) or group threat (e.g. Blalock, 1967) theories, and argues that ethnic struggles for resources and representation compromize the competitors' mu- 
tual trustworthiness and renders collective endeavours across ethnic boundaries unlikely (e.g. Hou and Wu, 2009). Some authors claim that if group threat theory is right, it is not ethnic diversity per se that undermines trust and cooperation. By contrast, the most contentious situations are polarized, meaning that two equal opponents face each other (Montalvo and Reynal-Querol, 2005; Esteban and Ray, 1994). While Alesina et al. (2003) find polarization not to be a superior predictor in their cross-national analysis, Dincer (2011) does in her analysis of US federal states and claims that "Conflict is less likely in societies in which fractionalization is minimal or maximal" (Dincer, 2011, p. 291). If these authors are correct in their interpretation of group threat theory, ethnic polarization (EP) is a better predictor of social cohesion than other diversity indices (H2). From their formal rent-seeking model Montalvo and Reynal-Querol (2005) derive the following index of ethnic polarization:

$$
\mathrm{EP}=1-\sum_{i=1}^{k}\left(\frac{0.5-s_{i}}{0.5}\right)^{2} s_{i}=4 \sum_{i=1}^{k} s_{i}^{2}\left(1-s_{i}\right)
$$

where $s_{i}$ is the share of ethnic category $i$ and $k$ is the number of categories. This index increases if one shifts the population between categories in such a way that categories become equal in size. The index ranges from 0 where either all people belong to one category or are divided across an infinitive amount of categories, to 1 where there are two groups of equal size.

\subsection{Ethno-cultural diversity}

What the above-discussed indices might be correlated with, but do not measure, is actual cultural diversity in norms, values, preferences, languages and meanings. Some indices try to capture these aspects of ethnic diversity and I suggest conceptualizing these as indices of ethno-cultural diversity. In regard to ethnic diversity and social cohesion, it makes sense to have a two-fold conceptualization of culture first as a moral system, and second as habituated routines of action and ways to do things. Each of these conceptualizations is linked to a potential explanation of the relation between social cohesion and ethnic 
diversity.

\subsubsection{Asymmetric distribution of preferences}

Seeing culture as a moral system that entails desirable goals and preferences (Parsons, 1972), ethnic diversity could mean disagreement about how a shared community should look like and which public goods should be provided, and could thereby lead to an under-provision of public goods (e.g. Kimenyi, 2006). In addition, Page (2008) has argued from a social choice perspective that asymmetrically distributed preferences may erode trust for the potential of disagreement they cause. In order to measure the asymmetric distribution of preferences that derive from cultural differences between ethnic groups, Baldwin and Huber (2010) rely on an extension of the Hirschman-Herfindahl Index that is weighted by cultural differences between groups. If differences in values and norms were central, a culturally weighted index of ethnic diversity (CED) should be a better predictor of social cohesion than other diversity indices (H3). Originally, Greenberg (1956) proposed this index, which he defined as:

$$
\mathrm{CED}=1-\sum_{i=1}^{k} \sum_{j=1}^{k} s_{i} s_{j} r_{i j}
$$

where $s$ is the share of ethnic category, $i$ or $j$ respectively and $k$ denotes the number of categories. $r_{i j}$ is a measure of the cultural distance between categories $i$ and $j$ that functions as a weight. $r_{i j}$ ranges between 0 if ethnicities are totally different in cultural terms and 1 if they are similar. ${ }^{2}$ As for the HHI measure, CED will take the value of 0 if all groups are similar in values or if there is only one group and 1 if each individual is an own group and they hold most different values. CED will by definition always be smaller or at best as large as the orthodox ethnic diversity index, because HHI can be regarded as a

${ }^{2}$ Consider a setting with three
$\left[\begin{array}{c}0.5 \\ 0.25 \\ 0.25\end{array}\right]\left[\begin{array}{lll}0.5 & 0.25 & 0.25\end{array}\right]=\left[\begin{array}{ccccc}0.25 & 0.125 & 0.125 \\ 0.125 & 0.0625 & 0.0625 \\ 0.125 & 0.0625 & 0.0625\end{array}\right]$.

The sum of the elements of this matrix is 1 . This is true for any vector with elements that sum up to 1 . 
special case of CED that assumes maximal differences between all groups.

In theory, asymmetric distributions of preferences originate from cultural differences, but economic differences might also be a cause. As Baldwin and Huber (2010) point out: "Group-based economic differences can lead to different group needs with respect to public goods, feelings of alienation or discrimination by some groups, different attitudes toward redistribution across groups, and different "class" identities by different groups" (Baldwin and Huber, 2010, p. 644). According to their study, the negative impact of ethnic diversity as found in cross-national studies is mostly due to economic inequality along ethnic lines. If economic differences along ethnic lines were important in the sub-national European case, ethnic group-based economic inequality (EGI) should be a better predictor of social cohesion than other diversity indices (H4). Baldwin and $\mathrm{Hu}-$ ber (2010) propose the following index of ethnic group-based income inequality:

$$
\mathrm{EGI}=\frac{1}{2 \bar{y}} \sum_{i=1}^{k} \sum_{j=1}^{k} s_{i} s_{j}\left|\bar{y}_{i}-\bar{y}_{j}\right|
$$

where $s$ is that share of category $i$ or $j$ and $k$ the number of categories. $\mid \bar{y}_{i}-$ $\bar{y}_{j} \mid$ denotes the difference in average income between $i$ and $j$, meaning that the average income difference between ethnicities serves as a weight. At first sight, the measure of ethnic group-based economic inequality is mathematically rather similar to the culturally weighted ethnic diversity index; instead of cultural differences, the average income differences serve as a weight. However, whereas $r_{i j}$ is negatively proportional (larger values denote smaller cultural differences), average income differences are not. Furthermore, the EGI is not subtracted from unity, but standardized by twice the grand average income. The EGI is hence rather different in interpretation, and best understood as a special case of the Gini index, for which each individual is assigned not his personal income, but his ethnic group's income. The index measures economic inequality between ethnic groups. 


\subsubsection{Coordination problems}

Instead of seeing culture as a moral system, Swidler (1986) proposes to conceive of it as habituated routines of action and ways to do things, which most importantly allow us to interact and communicate with others. A common language, metaphor usage as well as a common set of practices and schemes are necessary to communicate about the existence of shared preferences and to successfully coordinate the production of public goods (e.g. Deutsch, 1966). For this reason, some scholars claim ethnic diversity, seen as cultural diversity, leads to problems in the exchange of meaning and hence to coordination problems (e.g. Desmet et al., 2009; Habyarimana et al., 2007). Following the example of Lancee and Dronkers (2011), I suggest that in a European context language diversity does not seem to be the best indicator of coordination problems, since there are official first languages. A better way to test the implication of coordination problems in an immigration country is to investigate migrants' average host-country language skills and usage. If coordination problems are critical, average regional migrant host-country language skills and usage (LSU) is a better predictor of social cohesion than other diversity indices (H5), even though Lancee and Dronkers (2011) could not support this hypothesis for the Dutch case. As a simple measure, I suggest the mean of migrants' host-country language skills $l$ :

$$
\mathrm{LSU}=\frac{1}{n} \sum_{i=1}^{n} l_{i}
$$

\section{Data and methods}

As mentioned in the introduction, this paper relies on empirical analyses which are followed up by simulations. I describe the data and estimation strategy underlying the empirical analyses in this section, while the simulations and their set-up are elaborated later on in an own section. 


\subsection{The EDCA-Survey}

The analyses are based on the German sub-set of the Ethnic Diversity and Collective Action Survey (EDCAS), which was conducted from October 2009 to April 2010 (Schaeffer et al., 2011). The German sub-set consists of 7,500 completed and 479 discontinued standardized telephone interviews with participants who were at least 18 years of age. The survey has a $26 \%$ oversample of persons of immigrant origin, defined here as either being born abroad or having at least one parent who was born abroad. There is an additional $14 \%$ oversample of persons of Turkish origin. In order to prevent unaffordable screening costs, these latter participants were not sampled via random digit dialing as the other respondents but via their last names from telephone directories. The sample is stratified by 55 German cities and regions. These cities and regions were drawn from the nation's roughly 420 rural and urban "Kreise," the smallest administrative region for which nation-wide harmonized public data is available.

I analyse two cognitive indicators of social cohesion. The first, trust in neighbours, is identical to the measure Putnam (2007) uses. ${ }^{3}$ The second, collective efficacy, was originally developed by Sampson et al. (1999) and is supposed to measure a community's capacity to collectively solve neighbourhood problems, such as bulky waste lying about or street muggings and harassment. The EDCA-Survey measured collective efficacy with two items that are influenced by Friedrichs and Oberwittler (2007), who adapted the concept to suit the German context. $^{4}$

The two indicators differ in that trust in neighbours is a general indicator of neighbourhood relations, whereas collective efficacy asks about potentials for collective action for typical scenarios. There is no theoretical reason to assume the indicators to map differently on the competing diversity indices.

\footnotetext{
3 "Please indicate on a scale from 0 to 10 , how much you trust the people in your neighbourhood."

4 "In neighbourhoods there are different problems. Let me give you some examples:

On a public green space lies bulky waste. On a scale from zero to ten, how likely is it that people from your neighbourhood would jointly try to find a solution?

In a dark alley several people have been mugged. On a scale from zero to ten, [...]"
} 
The two dependent variables are regressed on the above-discussed indices as well as the number of years someone has lived in the neighbourhood, home ownership, education, gender, migration background, dummies indicating the religious confession and age. On the context level, the analyses control for East/West-German differences, the local unemployment rate, the population per square kilometre and the local crime rate. The descriptives of all dependent and independent variables, including the indices, are shown in Table A.4 in the appendix.

\subsection{The ethnic categories: Measuring $s_{i}$ for the HHI, EP, CED and EGI indices}

Calculating ethnic diversity indices necessitates information on the shares of ethnic categories. I use data of the Federal Office for Migration and Refugees' central register of foreign nationals ${ }^{5}$, which represents the most reliable source of information on the foreign population in Germany. The regional shares of people from all 193 fully recognized nations are available. Ethnic categories are thus defined by nationality in this study. This has the disadvantage that all people of immigrant origin who have acquired German citizenship are treated as German natives, meaning that diversity and polarization are probably underestimated. Unfortunately, data sources like the German micro census which allow for the identification of German citizens of immigrant origin do not yield regionally representative estimates of these populations. Note, however that I also discuss additional analyses with inflated indices that do not underestimate the overall share of persons of immigrant origin. Yet, the empirical results remain similar in conclusion.

In line with Baldwin and Huber (2010), I rely only on groups that represent a significant share of the local population. ${ }^{6}$ I set the minimum share to $0.05 \%$ of the local population, so that a category needs to have a share of at least $0.05 \%$ in one or more contexts that are covered by the EDCA-Survey. Since

\footnotetext{
${ }^{5}$ Federal Office for Migration and Refugees: www.bamf.de

${ }^{6}$ I also calculated an ethnic diversity index relying on all 193 national groups. Yet this index hardly differs because the squared group shares of size 0.004 and smaller do not have any numerical leverage so that the results are identical.
} 
many national categories of interest do not pass this threshold, I summed some categories to form a single category: North Africans (Moroccans, Tunisians, Algerians and Egyptians), persons from the Middle East (Emirates, Iraqis, Iranians, Jordanians, Kuwaitis, Lebanese, Omanis, Qataris, Syrians and Yemenites) and Afghanistan plus Pakistan. Including native Germans, this procedure results in 22 ethnic categories that relate to the following countries (or regions): North Africa, the Middle East, Afghanistan plus Pakistan, Austria, Bosnia and Herzegovina, Bulgaria, Croatia, France, Germany, Greece, Italy, Luxembourg, Netherlands, Poland, Portugal, Romania, Russia, Serbia, South Korea, Spain, Switzerland and Turkey.

3.3. The cultural and economic weights: Measuring $r_{i j}$ and $\left|\bar{y}_{i}-\bar{y}_{j}\right|$ for the $C E D$ and EGI indices

Calculating a culturally weighted index of ethnic diversity (CED), requires a weight $r_{i j}$ that denotes cultural differences between all ethnicities. Of course, Germany's Register of Foreign Nationals does not contain any information that would allow estimating cultural differences between nationalities. Instead, I use the latest available waves of the World Values Survey and European Values Study (2009) of 1981-2008. I estimated the mean value of Inglehart and Baker's (2000) traditionalism-secularism (TS) and materialism-post-materialism (PM) scales for each country ${ }^{7}$. Relying on these two scales, I calculated the average distances $(D)$ in values between all countries that are linked to the 22 ethnic categories discussed above. $^{8}$

Finally, I standardized $D$ to vary between 0 and 1 and thereby obtained $r_{i j}$. This approach relies on the strong assumption that average values of ethnic groups in Germany can be inferred from the values held by persons living in their countries of origin. This assumption is questionable, particularly because the largest minority group, persons of Turkish origin, began immigrating to

\footnotetext{
${ }^{7}$ The officially suggested procedure is described here: www.wvsevsdb.com/wvs/WVSIntegratedEVSWVSinstructions.jsp?Idioma=I

${ }^{8} D=\sqrt{\left(P M_{i}-P M_{j}\right)^{2}+\left(T S_{i}-T S_{j}\right)^{2}}$
} 
Germany nearly 50 years ago. I therefore regard the current operationalization as a proxy that demands for improvement by future research.

Just as cultural differences, income differences between ethnicities $\left|\bar{y}_{i}-\bar{y}_{j}\right|$ are not easy to come by. I use the German Micro Census to estimate average differences in monthly equivalence household income between the 22 ethnic categories of this study. These differences in equivalence household income are estimated for Germany at large and not for each of the 55 contexts, because of the Micro Census' is not representative on the regional level.

\subsection{Host-country language skills: Measuring $l_{i}$ for the LSU index}

To investigate the importance of average migrant language skills and usage within a region, I rely on the EDCA-Survey, which encompasses at least 24 respondents with migration background per context. I built a scale $l_{i}$ from three items: All respondents of the EDCA-Survey with a migration background were asked how often they had problems when speaking German, how often they speak German with their family members and how often they speak German with friends and acquaintances. An explorative principal components factor analysis shows that all items load on a single factor with factor loadings above 0.6. I use the solution of this factor analysis to predict a factor score for each individual. Note, however, that I did not consider respondents who were oversampled for the Turkish origin sample, since for this group no weights on their sampling propensity could be estimated. Overall, this means that average regional migrant host-country language skills and usage are aggregated from the EDCA-Survey itself and might thus be subject to large measurement errors.

\subsection{Modelling strategy}

Since the data is clustered in 55 cities and regions and the analyses include context level variables, a multi-level modelling strategy is needed. I estimate linear regression models with cluster-robust standard errors. Cluster-robust standard errors yield the advantage that the standard errors of parameters of context-level regressors are not underestimated (Angrist and Pischke, 2009, p. 
308-323). Moreover, they assume "no particular kind of within-cluster correlation nor a particular form of heteroskedasticity" (Wooldridge, 2003, p. 134), meaning they allow for any kind of upper and lower level heteroskedasticity. Random intercept models, an alternative estimation strategy, assume homoskedastic errors on both the individual and contextual level (e.g. RabeHesketh and Skrondal, 2008). For my analyses, this is an unrealistic assumption given that some contextual units are highly dense and socio-culturally heterogeneous cities like Berlin or Hamburg, and others are sparsely populated, homogeneous rural areas like Oberallgäu. Yet, results of estimations that rely on random intercept models are similar in conclusion.

Unfortunately, only $85.7 \%$ of the respondents answered all questions. This is particularly due to missing values on religious and educational background, but also the attitudinal scales. I thus estimate the models with ten multivariate imputations for the missing values on any of the variables. As suggested by Enders (2010), the imputation model consisted of all variables of the later analyses, including the interaction term discussed below. The imputation procedure includes respondents who discontinued the telephone interview, because these were part of the original sampling plan and should thus not be excluded. Results of estimations that rely on case wise deletion are similar in conclusion.

Because 55 clusters hardly allow to investigate the impact of various rather collinear diversity indices, I run separate models for each of the competing diversity measures. I then compare the respective model fits. While this procedure does not allow to test the competing indexes directly against one another, it informs us about which index yields the highest predictive power. However, comparing fit between the models is not straightforward, because they rely on multiply imputed data. Weakliem (2004) suggests to compare Akaike's Information Criterion (AIC) and the Bayesian Information Criterion (BIC). Unfortunately, it is an open domain of research how to estimate AIC and BIC values for models that rely on multiply imputed data. Instead, I use $R^{2}$ and Adjusted $R^{2}$ values that I estimate with Yula Marchenko's mibeta Stata ado-file, which is based on Harel's (2009) suggestions. Note that the AIC and BIC values of 
models that do not rely on the multiply imputed data support the same conclusions.

\section{Results}

4.1. Comparing the indices: Why is ethnic diversity associated with declines in social cohesion?

There are two studies on diversity effects in Germany, both of which rely on the German Socio-Economic Panel. Gundelach and Traunmüller (forthcoming) report a cross-sectional, negative association between ethnic diversity, particularly the share of Turkish nationals, and generalized trust, but not with norms of reciprocity. Stichnoth's (2012) fixed effects panel analysis confirms a negative effect of ethnic diversity on support for redistribution. My study complements their findings for two additional dependent, neighbourhood-related variables taken from a different data source: trust in neighbours (Table 2) and collective efficacy (Table 3). All indices of ethnic diversity (HHI), ethnic polarization (EP), culturally weighted ethnic diversity (CED) and ethnic group-based income inequality (EGI) show similar patterns of significant negative relations to the two dependent variables. Assuringly, the results for the two indicators of social cohesion, which are both measured on eleven point Likert scales, are even highly similar in terms of the strengths of the coefficients. Only migrants' average host country language skills (LSU), which differs most clearly in terms of operationalization, shows a significant relation neither to collective efficacy nor to trust in neighbours. One might argue that language skills only matter in settings with a sizeable proportion of minorities. Yet, additional analyses that are shown in the appendix in Table C.7, do not support the hypothesis that migrants' language skills matter more given larger shares of migrant minorities. These results replicate Lancee and Dronkers' (2011) findings for the Netherlands.

An important question pertains to differences between persons of immigrant origin and natives. As a robustness check, Model 7 introduces an interaction 
Table 2: Trust in neighbours and competing diversity indices

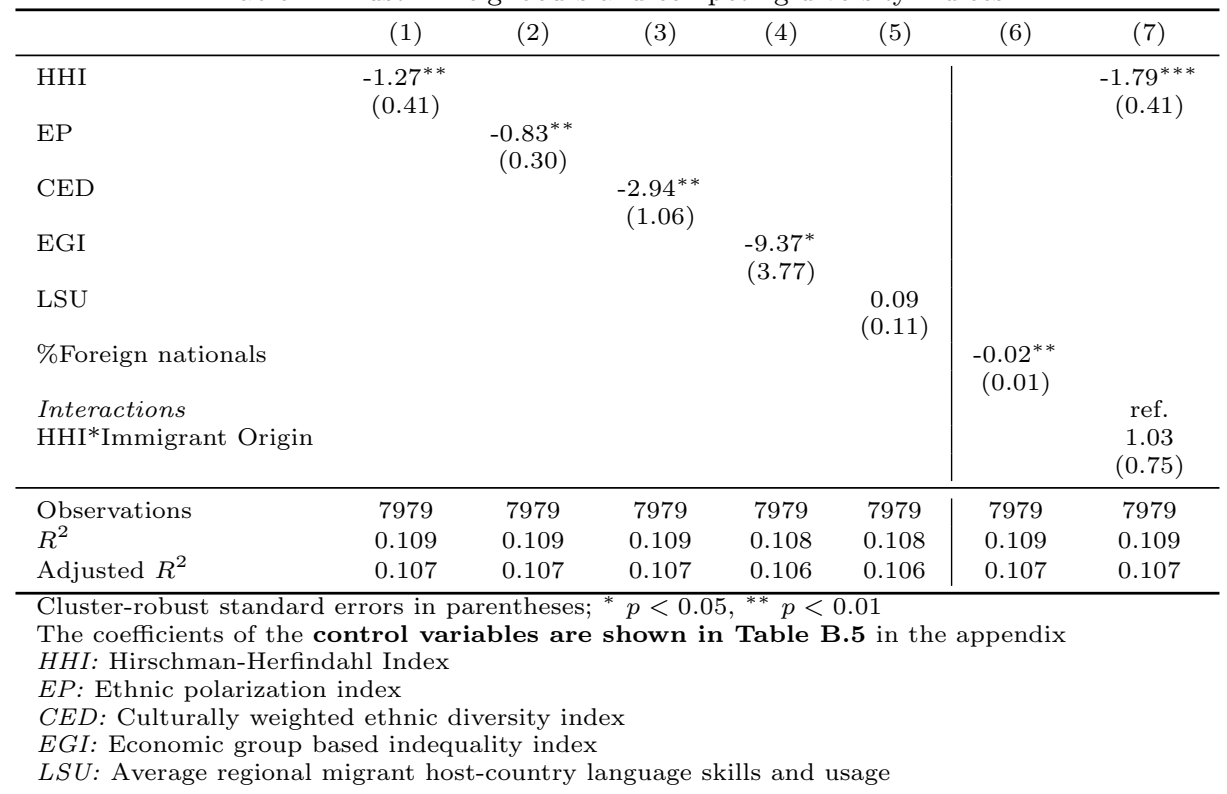

Table 3: Collective efficacy and competing diversity indices

\begin{tabular}{|c|c|c|c|c|c|c|c|}
\hline & (1) & $(2)$ & $(3)$ & (4) & (5) & (6) & (7) \\
\hline $\mathrm{HHI}$ & $\begin{array}{c}-1.20^{* * *} \\
(0.33)\end{array}$ & & & & & & $\begin{array}{c}-1.73^{* * *} \\
(0.39)\end{array}$ \\
\hline EP & & $\begin{array}{c}-0.84^{* *} \\
(0.26)\end{array}$ & & & & & \\
\hline CED & & & $\begin{array}{c}-2.82^{* *} \\
(0.85)\end{array}$ & & & & \\
\hline EGI & & & & $\begin{array}{c}-8.85^{* *} \\
(2.97)\end{array}$ & & & \\
\hline LSU & & & & & $\begin{array}{l}-0.23 \\
(0.14)\end{array}$ & & \\
\hline \%Foreign nationals & & & & & & $\begin{array}{c}-0.02^{* * *} \\
(0.01)\end{array}$ & \\
\hline $\begin{array}{l}\text { Interactions } \\
\mathrm{HHI}^{*} \text { Immigrant Origin }\end{array}$ & & & & & & & $\begin{array}{c}\text { ref. } \\
1.06 \\
(0.63)\end{array}$ \\
\hline Observations & 7979 & 7979 & 7979 & 7979 & 7979 & 7979 & 7979 \\
\hline$R^{2}$ & 0.074 & 0.074 & 0.074 & 0.074 & 0.073 & 0.074 & 0.074 \\
\hline Adjusted $R^{2}$ & 0.072 & 0.072 & 0.072 & 0.072 & 0.071 & 0.072 & 0.072 \\
\hline
\end{tabular}

The coefficients of the control variables are shown in Table B.6 in the appendix

$H H I$ : Hirschman-Herfindahl Index

$E P$ : Ethnic polarization index

$C E D$ : Culturally weighted ethnic diversity index

$E G I$ : Economic group based indequality index

$L S U$ : Average regional migrant host-country language skills and usage 
term to test whether diversity shows a significantly different association for persons of immigrant origin than for natives. However, in line with the theoretical mechanisms that are not majority-specific, none of the above-discussed relations is significantly different for persons of immigrant origin as compared to natives. ${ }^{9}$ This also holds for the other diversity indices as additional analyses, which are not displayed here, show.

Which of the competing significant indices, and hence of the associated explanations, yields the highest explanatory power? Unfortunately, the $R^{2}$ and Adjusted $R^{2}$ values do not allow any conclusion. There are hardly any differences in model fit between Models 1 to 5 , and the few variations are negligible. This means that none of the proposed indices shows any superior explanatory power in the sub-national German comparison. These results refute hypotheses H2 to H5 on the superiority of the refined diversity indices and yet neither provide support for hypothesis H1 about the superiority of the Hirschman-Herfindahl Index. While the common ethnic diversity index (HHI) is an adequate predictor, these results do not suggest in-group favouritism to be the main explanation. Correlations of 0.97 suggest the sobering conclusion that the competing indices all simply reflect the mere percent of foreign nationals (with the exception of the LSU). Indeed, Model 6 shows that results for the mere share of foreign nationals as alternative predictor are similar to the diversity indices. This means that at least in these analyses, the indices are invalid: they do not measure four theoretically distinct concepts, but across the board a fifth alternative; mere minority concentration. If this were true for other sub-national analyses, it could mean that much of the (European) research on ethnic diversity and social cohesion is actually about majority responses to minority concentration and tells us little about diversity effects per se. There seems to be more than mere majority reactions to minority concentration given that the relation also holds for persons of immigrant origin, as reported above. But the existing diversity indices do not

\footnotetext{
${ }^{9}$ The interaction terms indicate that for persons of immigrant origin the relations might be less strong. This is not surprising, given that for persons of immigrant origin more diverse areas also tend to be those where more in-group members live.
} 
operationalize this. This raises the question, under which conditions the competing indices become telling at all, i.e. statistically different from one another? Are such conditions likely in sub-national (European) settings? After all, the competing indices have generated insights in cross-national analyses.

\subsection{Simulations: When are competing diversity indicators informative?}

\subsubsection{Identifying three potential factors}

To answer why the competing indices are indistinguishable in my analyses, or vice versa under which conditions they are distinguishable, I simulated 500 contextual units with random population shares for up to 22 categories, and took the first category to represent a "native" population. I calculated the different diversity indices and the overall share of "minorities" for this simulated data. To calculate the culturally and economically weighted indices, I used the same weights as in the empirical analyses and assigned those to the 22 simulated categories. Figure 1 shows ten scatter plots for all pairwise combinations of the different indices. The sub-graphs' titles denote which index is shown on the $\mathrm{Y}$-axis (first named index) and which one on the $\mathrm{X}$-axis (second named index); for example: "a) HHI [Y-axis] by \%Minorities [X-axis]". The sub-graphs include both simulated (grey circles), and the 55 observed contexts (black dots). We see that the statistical (dis-)similarity of the indices has two dimensions: linear dependence and skedasticity. By facilitating the comparison between the empirically observed and the simulated contexts, Figure 1 helps identifying three potential reasons why the competing indices are statistically indistinguishable in my sub-national analyses.

First, the large share of native Germans might simply dominate the indices mathematically, or vice versa the range of minority shares covered in the sample of contextual units is too small. A sample needs to include contextual units with small and contextual units with large minority shares, which means that the 21 groups of foreign nationals that together make up less than 30 per cent of the population in each setting, have only little mathematical leverage, however culturally or economically distinct they are. Sub-graphs a) to d) in Figure 1 show 
Figure 1: Simulated relations between competing diversity indices

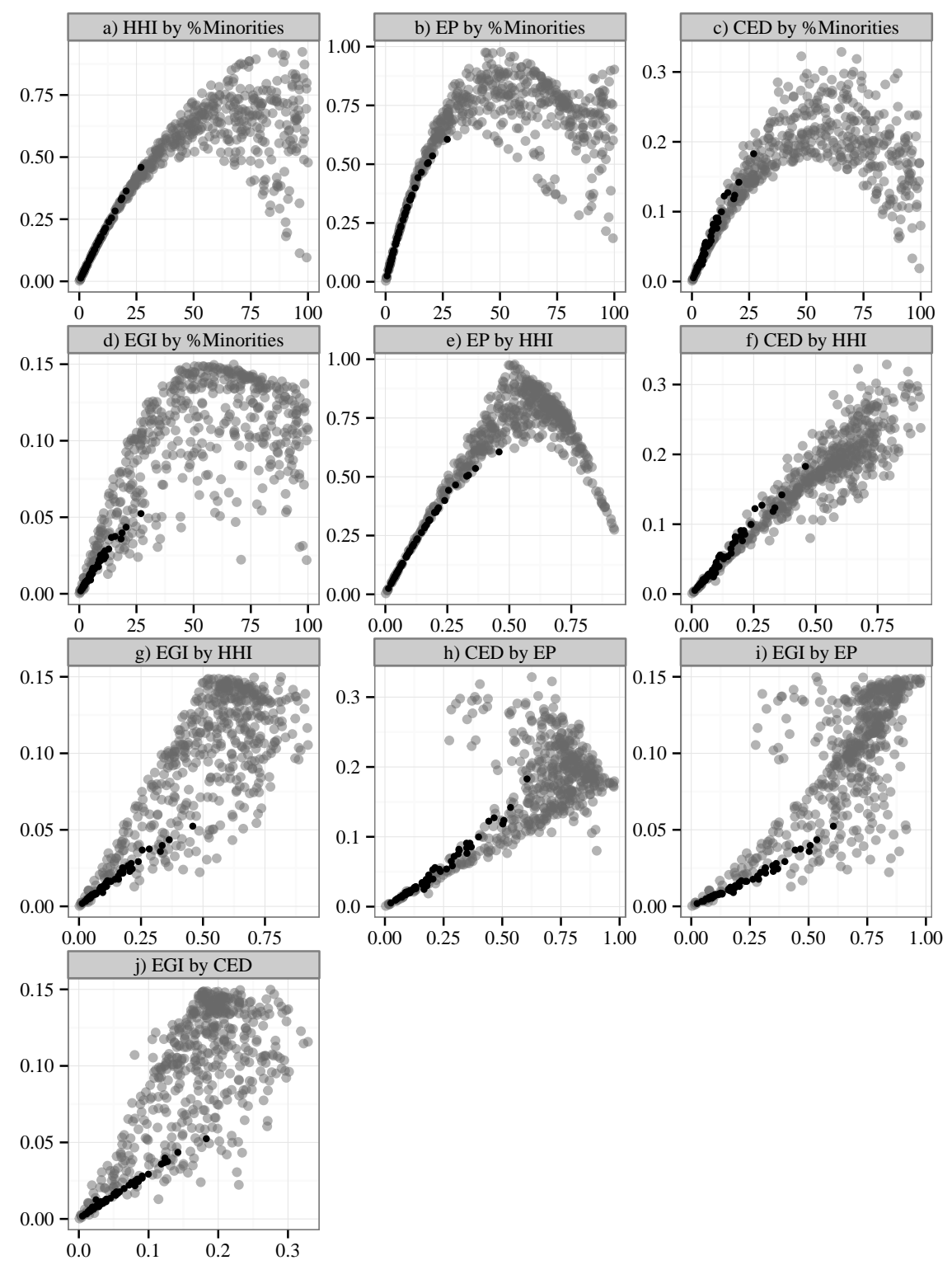

- Observed German data $\bullet$ Simulated data 
the four competing diversity indices against the percent minorities on the Xaxis. Within the range of minority shares that is covered by the EDCA-Survey (1 - 29 percent), the four indices can hardly be distinguished from the mere percentage of minorities both in terms of functional form and skedasticity. The weighted indices (CED and EGI) become distinct at much lower minority shares, which of course depends on the strength and variance of the weights. However, weighting achieves distinctiveness only in terms of skedasticity, but leaves the linear dependence unaffected. Important as it may be, the rather small range of the majority shares is unlikely the only reason. The German micro census does allow to estimate the accumulated regional share of people of immigrant origin, instead of foreign nationals, which make the basis of the here calculated diversity indices. However, across the 55 cities and regions the shares of foreign nationals and of people of immigrant origin correlate strongly $(\mathrm{r}=0.95)$. Yet, depending on the region, the share of people of immigrant origin is between a factor 1.2 and 3.2 higher than the share of foreign nationals. Following Koopmans and Veit's (forthcoming) example, I multiplied the percentages of the 21 minority groups by the above mentioned factors. The resulting group shares can be regarded as estimates of the 21 minority groups that include German nationals of immigrant origin. The operation decreases the majority shares and thereby expands the overall range of the minority shares. Yet, the above-presented empirical results remain similar in conclusion even if the competing indices rely on such inflated group shares. These additional analyses are shown in Tables C.8 and C.9 in the appendix.

The second reason why the indices are indistinguishable is that German regions hardly differ in their ethnic composition, or vice versa the degree to which a sample covers contextual units with diverse and contextual units with polarized ethnic compositions seems to be important. The simulated contexts of sub-graphs a) to d) in Figure 1 suggest more variation to be possible even within the small range of minority shares covered by the EDCA-Survey. For any given minority share, the ethnic composition of all observed cities and regions is always highly diverse. Taken from another angle, the ethnic polarization index 
is always minimal, because the majority never faces one homogeneous minority. Instead, the minority is always composed of a variety of subgroups. In contrast, the simulated data entails contextual units with polarized compositions too and therefore shows more skedasticity and less linear dependence between the indices. Whatever the share of minorities, simulated and observed data differ with respect to the fact that empirically there are no polarized situations where the majority faces only one single ethnic minority. One could also expect the indices to be indistinguishable because of the limitation to 22 groups. But this is an unlikely reason, given that the Hirschman-Herfindahl Index can vary between 0 and a maximum value of $1-\left(\frac{1}{k}\right)$ given $k$ groups (Fearon, 2003). The slope of this function is diminishing rapidly. For 22 groups this means that the maximum value of the HHI already lies at 0.95, as compared to the empirically observed maximum value of 0.46 , or 0.59 if inflated groups shares are utilized. This does not mean that the number of groups is generally negligible. It might be highly important with regard to the above-mentioned role of the ethnic composition. A totally polarized situation, can similarly be regarded as one where 20 of the 22 groups have population shares of 0 , or as one where there are only 2 groups. The simulated data entail such contexts frequently, in contrast to the empirically observed data. Varying numbers of groups are important with regard to how much ethnic compositions vary, i.e. the range of polarized to diverse contexts that can potentially be observed, as Figure 1 suggests.

Third, the weights that I apply both in the empirical analyses and simulation assume cultural and economic differences to be similar in every one of the 55 cities and regions. But maybe whether weights can vary by contextual unit matters. In cross-national analyses the cultural and economic weights vary by context, because the groups differ across the countries. Income differences between blacks and whites in the US are not similar to those between persons of Surinamese origin and native Dutch in the Netherlands. Since cultural and economic differences between ethnic groups possibly also vary across sub-national contexts, refined weights that vary by context could help to distinguish the weighted indices from one another. 
4.2.2. Testing the importance of the range of minority shares, varying ethnic compositions and weights that vary by context

Figure 1 only gives a visual impression that helps to identify potential reasons. To test the proposed reasons and inform future research about the conditions under which the indices become telling, I performed a second simulation that relies on a different strategy. Under 15 gradually different conditions, I each sampled 55 contextual units with random population shares of up to 22 categories, resembling the empirical analyses above. In the first condition, the category that is supposed to represent "natives" had to have a share of at least 70 percent. This means minority shares of the 55 simulated contexts vary in a range of 0 to 30 percent. In the following conditions, I subsequently lowered this restriction by five percent points, up until minorities shares could range between 0 and 100 percent. I estimated coefficients of determination $R^{2}$, i.e. the squared correlation between the indices, for each condition: how strongly do the indices determine each other in a sample when minorities can only make up to $30,35, \ldots, 100 \%$ of the contextual units' populations? I repeated this overall procedure 500 times and estimated the average $R^{2}$ value for each condition. This allows to study the importance of the range of minority shares covered. To study what happens if ethnic compositions hardly vary, I next repeated the procedure, but now restricted the routine to only simulate diverse contexts where there are always 22 groups. In other words, all groups have shares larger than 0, just as in the 55 observed German cities and regions. Finally, I conducted the two versions of these simulations both with constant weights and weights that vary over the contexts. To achieve this, I simulated a 22-by-22 matrix of random values between 0.5 and 1.5 for each simulated context. I then multiplied it element-wise to the matrices containing the economic and cultural weights. ${ }^{10}$ This means that the cultural and economic differences between the 22 groups are randomly increased or decreased by up to $50 \%$. Figure 2 visualizes one par-

\footnotetext{
${ }^{10}$ Since the cultural weights have a maximum value of 1 , I truncated all values larger than that to 1 .
} 
ticular sample out of numerous simulated ones and thus gives an impression of what underlays the below discussed results. It shows scatter plots for a sample of 55 simulated contextual units where minorities shares were allowed to range from 0 to $100 \%$ and where the ethnic composition within each contextual unit is always diverse, i.e. there are always 22 groups and thus not a single polarized setting. The figure shows impressively how the latter constraint of allowing no polarized ethnic compositions generates a stark resemblance between simulated and actually observed data. Furthermore, the filled grey circles represent contextual units that have been weighted with constant weights, while the hollow ones represent units that have been weighted with context varying weights. The negligible difference between filled and hollow circles already suggests that context varying weights might be of less importance.

The overall results of the simulations are visualized in the six sub-graphs of Figure 3. Each sub-graph shows the $R^{2}$ values among the indices against the range of minority shares that is covered in the sample. The sub-graphs start out at the range of 0 to 30 percent minorities, which is the range covered in the above-discussed empirical analyses. Like a cross-table, the sub-graphs of Figure 3 are arranged according to two dimensions. The graphs in column 1 show results for simulated samples that include varying ethnic compositions, i.e. from polarized to diverse. The graphs in column 2 show results for simulated samples that keep a constant number of 22 groups and are thus always diverse, i.e. the ethnic composition is not varying between diverse and polarized in these samples. The graphs of row a) show results for $R^{2}$ values among indices that do not rely on any weighting (among HHI, EP and \%Minorities), while the results shown in row b) and c) always involve at least one index that relies on weighting (CED or EGI). The results shown in row b) rely on constant weights, and those of row c) on weights that vary by context. All figures entail cut-off lines at $R^{2}=0.8$ (red dashed line). I take values below to indicate unproblematic levels of mutual determination, i.e. collinearity. ${ }^{11}$ I include a line at $R^{2}=0.6$ (grey

${ }^{11} \mathrm{An} R^{2}=0.8$ indicates a tolerance of 0.20 and a VIF of 5 respectively. 
Figure 2: Simulated relations between competing diversity indices, only diverse contexts with 22 groups
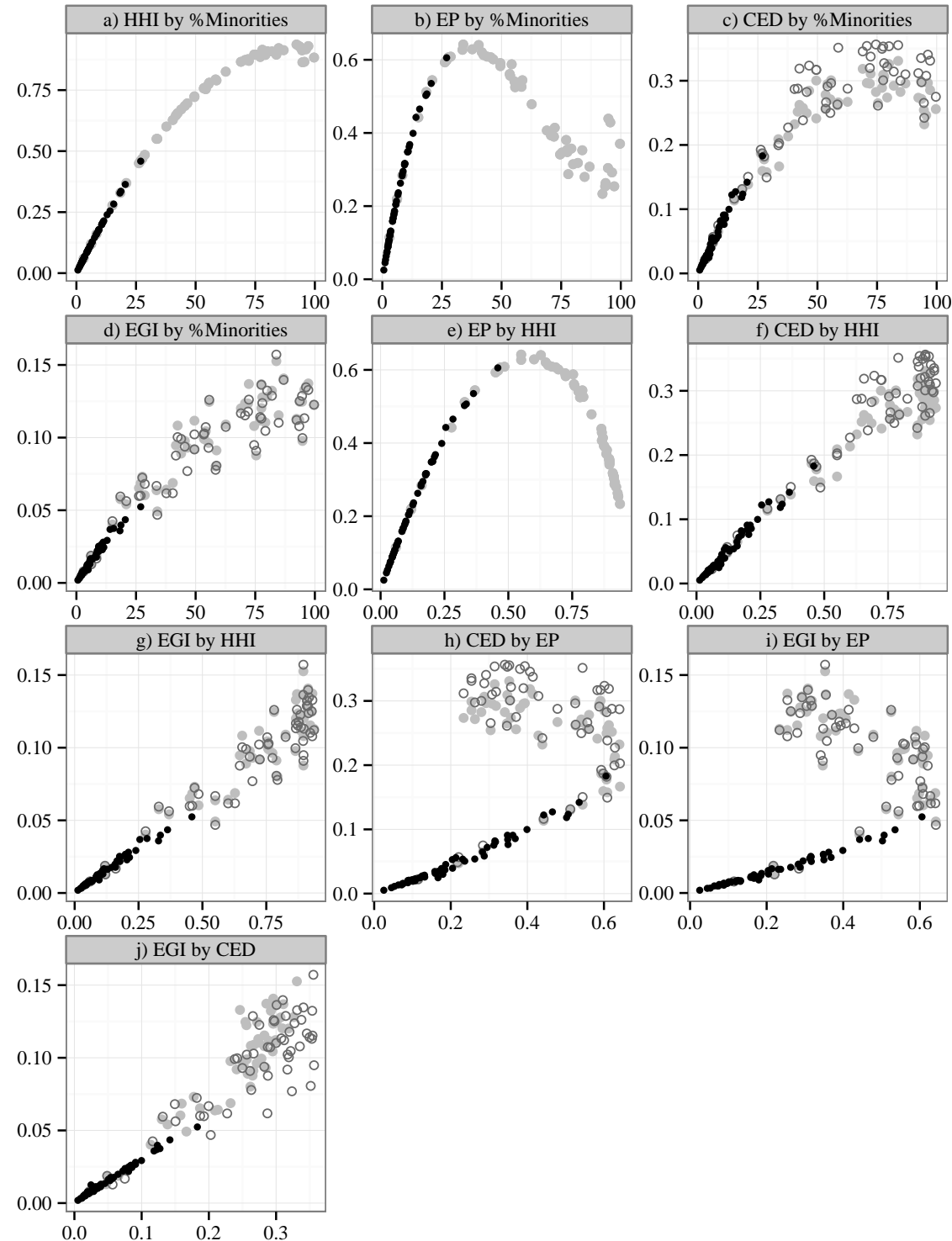

$$
\begin{array}{ll|l}
\text { - } & \text { Observed German data } & \circ \\
\text { - Simulated data (constant weights) }
\end{array}
$$


dashed line) too, because under the additional consideration of control variables, such as the local unemployment rate or population density, potential collinearity might increase again.

Much could be said about the degree of similarity between concrete indices. But given the number of overall 34 comparisons, I refrain from such a detailed discussion and focus on the general pattern. Figure 3 shows a decline in the high coefficients of determination between the indices as the range of minority shares increases. As expected, the range of minority shares covered in a sample is a main reason why indices capture distinctive information. Overall, a range of up to 80 percent minority shares allows to disentangle most indices from one another, as long as polarized and diverse contexts are part of the sample (see below). This is of course far from the actually observed range and researchers might need to think about whether there are other contexts than cities and regions, such as school classes or work teams, where concentrations of up to that strength can be found.

Weighting is another factor. The increased skedasticity lowers the overall levels of determination. Focussing on simulations that entail polarized and diverse contexts (column 1) we see that because of the overall shift, many weighted indices become distinct from their counterparts even if the range of minority shares covered varies from 0 to 50 percent only. If the range reaches up to 80 percent, weighted indices seem to be safe to use with $R^{2}$ values lower than 0.6. This is particularly true when weights vary by context, as the comparison of sub-graphs 1b) and 1c) shows quite drastically. These observations of course depend on the weights utilized. For countries with smaller or larger income differences between ethnic groups, or studies with better proxies of cultural differences, the shift could differ in strength. Weighting, particularly context specific weighting, complements the role of the range of minority concentration: indices that rely on varying weights do not seem to show steeper declines in mutual determination as the range of minority share increases.

Finally, whether ethnic compositions vary between polarized and diverse (column 1) is not a complementary factor that simply decreases the $R^{2}$ values 
Figure 3: Coefficients of determination among competing diversity indices

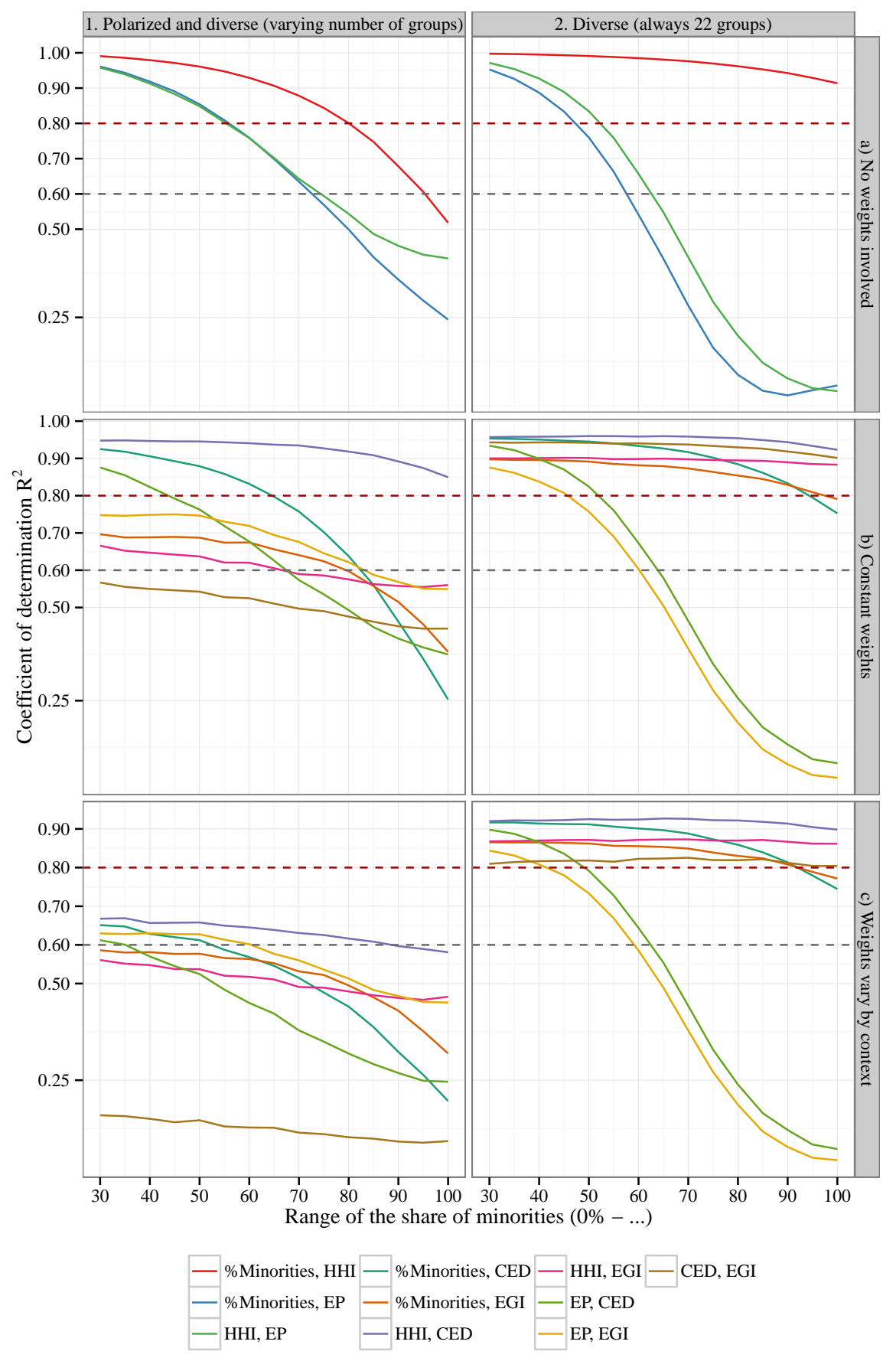


additionally. Instead, it affects the way both weighting and the range of minority shares matter. Generally, the sobering implication is that as ethnic compositions are always diverse (column 2), increasing ranges of minority shares only allow a general distinction of diversity and minority concentration from polarization indices. Diversity, culturally or economically weighted diversity and minority concentration, however, are indistinguishable if there are always 22 groups. Weighting, and particularly context-specific weighting, decreases the levels of mutual determination only marginally. In more polarized situations, only few weights apply and depending on the groups, may change the context's diversity considerably. If there are 22 groups in each context, however, all weights always apply. This means that all contexts face rather similar weighting. Principally, this is also true for context-specific weights, although they decrease $R^{2}$ values somewhat. Overall, these results are particularly disillusioning as the simulated samples of exclusively diverse contextual units where there are always 22 groups (column 2) better resemble the sub-national situation in many countries, and certainly the above-presented empirical analyses. The $R^{2}$ values at minority ranges up to 30 percent are quite similar to the ones observed in the EDCASurvey. This is not at all the case for the predictions of the simulated samples that include both polarized contextual units and diverse contextual units, i.e. samples that have varying ethnic compositions. It again highlights the need to think about other contexts than cities and regions, that entail a broader range of ethnic compositions.

\section{Conclusion}

An ever-growing number of studies investigates the relation between ethnic diversity and social cohesion, but the results are mixed. In cross-national research, some scholars suggest promising alternatives to the orthodox HirschmanHerfindahl Index. These indices, such as culturally and economically weighted ethnic diversity, can be regarded as operationalizations of competing theoretical explanations. Testing the explanatory power of these competing indices against 
one another potentially answers why ethnic diversity is associated with declines in social cohesion. This study sought to expand upon previous research by testing the applicability of this approach in a sub-national analyses of 55 German cities and regions.

The analyses do confirm a negative relation between ethnic diversity neighbourhood social cohesion in Germany, and thereby complement existing studies. Yet, the main question, what drives ethnic diversity effects, could not be answered. Coordination problems are unlikely to be the reason. Migrants' average host-country language skills did not show a significant relation to any of the indicators of social cohesion. Along with the results of Habyarimana et al. (2007) and Lancee and Dronkers (2011), this rather speaks against coordination problems as a driving force behind the diversity effects. In comparison to this clear-cut result, the lesson concerning the other indices is sobering. Their comparison does not provide any further insights beyond their common association with social cohesion, because the supposedly competing indices are statistically indistinguishable, and equivalent to the mere percentage of foreign nationals in these analyses. This renders them invalid in the given setting, because for these German contextual units they do not measure the four theoretically distinct concepts they claim to measure. Worse yet, this raises the question in how far existing studies actually provide evidence for diversity effects rather than majority responses to minority concentration?

Since comparing these indices did provide insights in previous cross-national analyses, I conducted follow-up simulations to identify the general conditions under which the competing indices become valid operationalizations of (culturally and economically weighted) ethnic diversity and polarization. In Germany, the most ethnically diverse city has a share of foreign nationals of about 29 percent. Yet, the simulations show that minority shares need to range considerably in order for the indices to be distinguishable and sufficiently distinct from mere minority concentration; samples need to cover contextual units with small and contextual units with large minority shares. Weighting indices by economic and cultural differences between ethnic groups, and particularly fine-grained weight- 
ing that is context specific, further helps to distinguish indices from one another. But generally, weighting is of lesser importance due to a third crucial factor: the variety of ethnic compositions covered. In Germany, the majority never faces one homogeneous minority. Instead, the minority is always composed of a variety of ethnic (sub)groups. In this regard the simulations indicate the disillusioning lesson that when ethnic compositions are always diverse and never polarized, increasing ranges of minority shares only allow a general distinction of diversity from polarization. Weighting has hardly any leverage under such circumstances, and diversity cannot be distinguished from minority concentration. This result is highly disillusioning because an immigrant population that is composed of a variety of ethnic groups best resembles the situation in most European, and arguably also many North American, cities and regions.

These findings have important implications for (European) sub-national research. They question the use of diversity indices to study ethnic diversity effects. Researchers who analyze secondary data should check whether the indices utilized can actually be distinguished from minority concentration empirically and whether their results hold for persons of immigrant origin if they wish to provide evidence for diversity effects. If researchers aim to conduct an own survey they should carefully design a stratified sample that includes both polarized and diverse compositions for a range of minority shares that is as large as possible. Alternatively, future research might exploit other contextual units than cities and regions to study diversity effects, particularly since more local diversity measures seem to be the better predictors (Dinesen and Sønderskov, 2011). Some neighbourhoods in Amsterdam, Berlin, London, Paris or Brussels potentially have ethnic compositions that are not characterized by a clear majority of natives, and are sometimes even rather polarized. Sturgis et al. (2011), however, warn against drawing neighbourhood boundaries that are meaningless to individuals. Another possibility might thus be to investigate school classes (e.g. Dinesen, 2011), organizations, or work groups.

Finally, my research highlights that both theory and methodology neglect as a special case the typical European situation where there is a clear, dom- 
inant majority. Ethnic compositions that are typical for European cities and regions are theoretically treated as an intermediary stage between the idealtypical situations of total homogeneity and total (maybe culturally or economically weighted) diversity or polarization respectively. Given the sheer absence of strong diversity or polarization in most parts of Europe, theory and methodology development should be concerned more with the particular implications of typical compositions, rather than non-existent ideal typical ones. One solution might be relational diversity indices as proposed by Koopmans and Schaeffer (2012), which distinguish between the perspectives of different ethnic groups within the same context. Such a relational approach might also tackle the problem that the existing diversity indices are not well suited to study minority reactions to diversity. In many instances, they simply measure the share of minorities and thus existing indices note an increase in diversity as the own group share grows. This is unfortunate since we would expect the share of the own group to be positively associated with levels of trust, in contrast to diversity.

\section{Acknowledgements}

I wish to thank Sarah Carol, Jan-Paul Heisig, Marc Helbling, Jutta Höhne, Marc Keuschnigg and three anonymous reviewers for helpful comments and ideas. I am particularly grateful to Ruud Koopmans who suggested investigating competing diversity indices and conducting follow-up simulations in the first place. This work was funded by the German Federal Ministry of Family, Elderly, Women and Youth. 
Alesina, A., Baqir, R., Easterly, W., 1999. Public goods and ethnic divisions. Quarterly Journal of Economics 114 (4), 1243-1284.

Alesina, A., Devleeschauwer, A., Easterly, W., Kurlat, S., Wacziarg, R., 2003. Fractionalization. Journal of Economic Growth 8 (2), 155-194.

Alesina, A., La Ferrara, E., 2002. Who trusts others? Journal of Public Economics 85 (2), 207-234.

Angrist, J. D., Pischke, J., 2009. Mostly Harmless Econometrics: An Empiricist's Companion. Princeton University Press, Princeton.

Baldwin, K., Huber, J. D., 2010. Economic versus cultural differences: Forms of ethnic diversity and public goods provision. American Political Science Review 104 (04), 644-662.

Blalock, H. M., 1967. Toward a Theory of Minority-Group Relations. Wiley, New York.

Brown, R., 2000. Social identity theory: Past achievements, current problems and future challenges. European Journal of Social Psychology 30 (6), 745-778.

Chan, J., To, H.-P., Chan, E., 2006. Reconsidering social cohesion: Developing a definition and analytical framework for empirical research. Social Indicators Research 75 (2), 273-302.

Desmet, K., Ortuno-Ortin, I., Weber, S., 2009. Linguistic diversity and redistribution. Journal of the European Economic Association 7 (6), 1291-1318.

Deutsch, K. W., 1966. Nationalism and Social Communication: An Inquiry into the Foundations of Nationality. MIT Press, Cambridge.

Dincer, O. C., 2011. Ethnic diversity and trust. Contemporary Economic Policy 29 (2), 284-293.

Dinesen, P. T., 2011. Me and Jasmina down by the schoolyard: An analysis of the impact of ethnic diversity in school on the trust of schoolchildren. Social Science Research 40 (2), 572-585. 
Dinesen, P. T., Sønderskov, K. M., 2011. Generalised trust and ethnic diversity of the micro-context. In: 6th ECPR General Conference. Reykjavik.

Enders, C. K., 2010. Applied Missing Data Analysis. Guilford Press, New York.

Esteban, J., Ray, D., 1994. On the measurement of polarization. Econometrica $62(4), 819-851$.

Fearon, J. D., 2003. Ethnic and cultural diversity by country. Journal of Economic Growth 8 (2), 195-222.

Friedrichs, J., Oberwittler, D., 2007. Soziales Kapital in Wohngebieten. In: Franzen, A., Freitag, M. (Eds.), Sozialkapital: Grundlagen und Anwendungen. Kölner Zeitschrift für Soziologie und Sozialpsychologie (Sonderheft No. 47), Wiesbaden, pp. 450-486.

Gijsberts, M., van der Meer, T., Dagevos, J., 2011. 'Hunkering down' in multiethnic neighbourhoods? The effects of ethnic diversity on dimensions of social cohesion. European Sociological Review doi: 10.1093/esr/jcr022.

Greenberg, J. H., 1956. The measurement of linguistic diversity. Language 32 (1), 109-115.

Gundelach, B., Traunmüller, R., forthcoming. Beyond generalized trust: Norms of reciprocity as an alterntive form of social capital in an assimilationist integration regime. Political Studies.

Habyarimana, J., Humphreys, M., Posner, D. N., Weinstein, J. M., 2007. Why does ethnic diversity undermine public goods provision? American Political Science Review 101 (04), 709-725.

Harel, O., 2009. The estimation of R2 and adjusted R2 in incomplete data sets using multiple imputation. Journal of Applied Statistics 36 (10), 1109-1118.

Hirschman, A. O., 1964. The paternity of an index. The American Economic Review 54 (5), 761-762. 
Hou, F., Wu, Z., 2009. Racial diversity, minority concentration, and trust in Canadian urban neighborhoods. Social Science Research 38 (3), 693-716.

Inglehart, R., Baker, W. E., 2000. Modernization, cultural change, and the persistence of traditional values. American Sociological Review 65 (1), 19-51.

Kimenyi, M. S., 2006. Ethnicity, governance and the provision of public goods. Journal African Economics 15 (1), 62-99.

Koopmans, R., Schaeffer, M., 2012. Relationale Diversitätsindizes? Vorschlag und emprischer Test gruppenspezifischer Diversitätsmaße. In: 36. Kongress der Deutschen Gesellschaft für Soziologie. Bochum.

Koopmans, R., Veit, S., forthcoming. Cooperation in ethnically diverse neighborhoods: A lost letter experiment. Political Psychology.

Lancee, B., Dronkers, J., 2011. Ethnic, religious and economic diversity in Dutch neighbourhoods: Explaining quality of contact with neighbours, trust in the neighbourhood and inter-ethnic trust. Journal of Ethnic and Migration Studies $37(4), 597-618$.

Miguel, E., Gugerty, M. K., 2005. Ethnic diversity, social sanctions, and public goods in Kenya. Journal of Public Economics 89 (11-12), 2325-2368.

Montalvo, J. G., Reynal-Querol, M., 2005. Ethnic diversity and economic development. Journal of Development Economics 76 (2), 293-323.

Olzak, S., 1992. The Dynamics of Ethnic Competition and Conflict. Stanford University Press, Stanford.

Page, S. E., 2008. The Difference: How the Power of Diversity Creates Better Groups, Firms, Schools, and Societies. Princeton University Press, Princeton.

Parsons, T., 1972. Culture and social systems revisited. Social Science Quarterly $53(2), 253-266$. 
Portes, A., Vickstrom, E., 2011. Diversity, social capital, and cohesion. Annual Review of Sociology 37, 461-479.

Putnam, R. D., 2007. E pluribus unum: Diversity and community in the twentyfirst century. Scandinavian Political Studies 30 (2), 137-174.

Rabe-Hesketh, S., Skrondal, A., 2008. Multilevel and Longitudinal Modeling using Stata. Stata Press, College Station.

Rao, C. R., 1982. Diversity and dissimilarity coefficients: A unified approach. Theoretical Population Biology 21 (1), 24-43.

Sampson, R. J., Morenoff, J. D., Earls, F., 1999. Beyond social capital: Spatial dynamics of collective efficacy for children. American Sociological Review $64(5), 633-660$.

Savelkoul, M., Gesthuizen, M., Scheepers, P., 2011. Explaining relationships between ethnic diversity and informal social capital across European countries and regions: Tests of constrict, conflict and contact theory. Social Science Research 40 (4), 1091-1107.

Schaeffer, M., 2012. Ethnic Fractionalisation and Social Cohesion: The Relation Between Immigration, Ethnic Fractionalisation and Potentials for Civic, Collective Action in Germany. Dissertation, Universiteit van Amsterdam Digital Academic Repository: http://dare.uva.nl/en/record/411335.

Schaeffer, M., Koopmans, R., Veit, S., Wagner, M., Wiedner, J., 2011. The Ethnic diversirty and collective action survey (EDCAS). WZB Discussion Paper Series No. SP IV 2011-701.

Stichnoth, H., 2012. Does immigration weaken natives' support for the unemployed? Evidence from Germany. Public Choice 151 (3), 631-654.

Sturgis, P., Brunton-Smith, I., Read, S., Allum, N., 2011. Does ethnic diversity erode trust? Putnam's 'hunkering down' thesis reconsidered. British Journal of Political Science 41 (01), 57-82. 
Swidler, A., 1986. Culture in action - symbols and strategies. American Sociological Review 51 (2), 273-286.

Tajfel, H., Billig, M. G., Bundy, R. P., Flament, C., 1971. Social categorization and intergroup behaviour. European Journal of Social Psychology 1 (2), 149 178.

Tolsma, J., van der Meer, T., Gesthuizen, M., 2009. The impact of neighbourhood and municipality characteristics on social cohesion in the Netherlands. Acta Politica 44 (3), 286-313.

van der Meer, T., Tolsma, J., 2011. Unity in diversity? Ethnic diversity and its supposed detrimental effects on social cohesion: A review of 56 empirical studies. In: 6th ECPR General Conference. Reykjavik, pp. 1-46.

Vermeulen, F., Tillie, J., van de Walle, R., 2011. Different effects of ethnic diversity on social capital: Density of foundations and leisure associations in Amsterdam neighbourhoods. Urban Studies doi: 10.1177/0042098011403016.

Wasserman, S., Faust, K., 1994. Social Network Analysis: Methods and Applications. Cambridge University Press, Cambridge.

Weakliem, D. L., 2004. Introduction to the special issue on model selection. Sociological Methods \& Research 33 (2), 167.

Wooldridge, J. M., 2003. Cluster-sample methods in applied econometrics. The American Economic Review 93 (2), 133-138.

World Values Survey Association, 2009. European and world values surveys four-wave integrated data file 1981-2008. Madrid www.wvsevsdb.com/wvs/WVSData.jsp. 
${ }_{857}$ Appendix A. Descriptives

Table A.4: Descriptive statistics

\begin{tabular}{|c|c|c|c|c|}
\hline & Mean & $\mathrm{SD}$ & Min & $\operatorname{Max}$ \\
\hline Dependent Variables & ref. & & & \\
\hline Trust in Neighbours & 6.78 & 2.53 & 0 & 10 \\
\hline Collective Efficacy & 6.19 & 2.57 & 0 & 10 \\
\hline Individual Level Variables & ref. & & & \\
\hline Age & 48.31 & 16.92 & 18 & 97 \\
\hline Education, reference: Low & 0.09 & 0.28 & 0 & 1 \\
\hline Middle & 0.61 & 0.49 & 0 & 1 \\
\hline High & 0.30 & 0.46 & 0 & 1 \\
\hline Employed & 0.61 & 0.49 & 0 & 1 \\
\hline Years in the Nbh. & 19.05 & 16.09 & 0 & 90 \\
\hline Home Owner & 0.45 & 0.50 & 0 & 1 \\
\hline Female & 0.54 & 0.50 & 0 & 1 \\
\hline Immigrant origin & 0.43 & 0.49 & 0 & 1 \\
\hline Married & 0.52 & 0.50 & 0 & 1 \\
\hline Religion, reference: Atheist & 0.40 & 0.49 & 0 & 1 \\
\hline Protestant & 0.18 & 0.38 & 0 & 1 \\
\hline Catholic & 0.19 & 0.39 & 0 & 1 \\
\hline Muslim & 0.16 & 0.37 & 0 & 1 \\
\hline Other & 0.07 & 0.25 & 0 & 1 \\
\hline Contextual Level Variables & ref. & & & \\
\hline East Germany & 0.13 & 0.34 & 0 & 1 \\
\hline Local Unemployment Rate & 8.54 & 3.39 & 3.27 & 14.76 \\
\hline Population Density & 1.53 & 1.36 & 0.04 & 4.27 \\
\hline Crime Rate & 0.09 & 0.04 & 0.03 & 0.16 \\
\hline Ethnic Diversity Indices & ref. & & & \\
\hline HHI & 0.16 & 0.11 & 0.01 & 0.46 \\
\hline CED & 0.07 & 0.04 & 0.01 & 0.18 \\
\hline $\mathrm{EP}$ & 0.27 & 0.16 & 0.03 & 0.61 \\
\hline LSU & 0.02 & 0.20 & -0.61 & 0.44 \\
\hline EGI & 0.02 & 0.01 & 0.00 & 0.05 \\
\hline \%Foreign nationals & 10.94 & 7.16 & 1.10 & 29.71 \\
\hline
\end{tabular}


Appendix B. Results for the control variables

Table B.5: Results for the control variables of Table 2 (trust in neighbours)

\begin{tabular}{|c|c|c|c|c|c|c|c|}
\hline & (1) & (2) & (3) & (4) & (5) & (6) & (7) \\
\hline Individual level & ref. & ref. & ref. & ref. & ref. & ref. & ref. \\
\hline \multirow[t]{2}{*}{ Age } & $0.02^{* * *}$ & $0.02^{* * *}$ & $0.02^{* * *}$ & $0.02^{* * *}$ & $0.02^{* * *}$ & $0.02^{* * *}$ & $0.02^{* * *}$ \\
\hline & $(0.00)$ & $(0.00)$ & $(0.00)$ & $(0.00)$ & $(0.00)$ & $(0.00)$ & $(0.00)$ \\
\hline \multirow{3}{*}{$\begin{array}{l}\text { Education, referece: Low } \\
\text { Middle }\end{array}$} & ref. & ref. & ref. & ref. & ref. & ref. & ref. \\
\hline & 0.18 & 0.18 & 0.18 & 0.18 & 0.19 & 0.18 & 0.18 \\
\hline & $(0.10)$ & $(0.10)$ & $(0.10)$ & $(0.10)$ & $(0.10)$ & $(0.10)$ & $(0.10)$ \\
\hline \multirow[t]{2}{*}{ High } & $0.43^{* * *}$ & $0.43^{* * *}$ & $0.43^{* * *}$ & $0.43^{* * *}$ & $0.44^{* * *}$ & $0.43^{* * *}$ & $0.43^{* * *}$ \\
\hline & $(0.11)$ & $(0.11)$ & $(0.11)$ & $(0.11)$ & $(0.11)$ & $(0.11)$ & $(0.11)$ \\
\hline \multirow[t]{2}{*}{ Employed } & 0.06 & 0.05 & 0.06 & 0.06 & 0.05 & 0.06 & 0.05 \\
\hline & $(0.06)$ & $(0.06)$ & $(0.06)$ & $(0.06)$ & $(0.06)$ & $(0.06)$ & $(0.06)$ \\
\hline \multirow[t]{2}{*}{ Years in the Nbh. } & $0.01^{* * *}$ & $0.01^{* * *}$ & $0.01^{* * *}$ & $0.01^{* * *}$ & $0.01^{* * *}$ & $0.01^{* * *}$ & $0.01^{* * *}$ \\
\hline & $(0.00)$ & $(0.00)$ & $(0.00)$ & $(0.00)$ & $(0.00)$ & $(0.00)$ & $(0.00)$ \\
\hline \multirow[t]{2}{*}{ Home Owner } & $0.55^{* * *}$ & $0.55^{* * *}$ & $0.55^{* * *}$ & $0.55^{* * *}$ & $0.55^{* * *}$ & $0.55^{* * *}$ & $0.55^{* * *}$ \\
\hline & $(0.05)$ & $(0.05)$ & $(0.05)$ & $(0.05)$ & $(0.05)$ & $(0.05)$ & $(0.05)$ \\
\hline \multirow[t]{2}{*}{ Female } & $0.17^{* *}$ & $0.17^{* *}$ & $0.17^{* *}$ & $0.17^{* *}$ & $0.16^{* *}$ & $0.17^{* *}$ & $0.16^{* *}$ \\
\hline & $(0.05)$ & $(0.05)$ & $(0.05)$ & $(0.05)$ & $(0.05)$ & $(0.05)$ & $(0.05)$ \\
\hline \multirow[t]{2}{*}{ Immigrant origin } & $-0.38^{* * *}$ & $-0.38^{* * *}$ & $-0.38^{* * *}$ & $-0.38^{* * *}$ & $-0.39^{* * *}$ & $-0.38^{* * *}$ & $-0.55^{* * *}$ \\
\hline & $(0.08)$ & $(0.08)$ & $(0.08)$ & $(0.08)$ & $(0.08)$ & $(0.08)$ & $(0.13)$ \\
\hline \multirow[t]{2}{*}{ Married } & $0.39^{* * *}$ & $0.39^{* * *}$ & $0.39^{* * *}$ & $0.39^{* * *}$ & $0.38^{* * *}$ & $0.39^{* * *}$ & $0.39^{* * *}$ \\
\hline & $(0.05)$ & $(0.05)$ & $(0.05)$ & $(0.05)$ & $(0.05)$ & $(0.05)$ & $(0.05)$ \\
\hline \multirow{3}{*}{$\begin{array}{l}\text { Religion, reference: Atheist } \\
\text { Protestant }\end{array}$} & ref. & ref. & ref. & ref. & ref. & ref. & ref. \\
\hline & $0.40^{* * *}$ & $0.40^{* * *}$ & $0.40^{* * *}$ & $0.40^{* * *}$ & $0.40^{* * *}$ & $0.40^{* * *}$ & $0.40^{* * *}$ \\
\hline & $(0.08)$ & $(0.08)$ & $(0.08)$ & $(0.08)$ & $(0.08)$ & (0.08) & $(0.07)$ \\
\hline \multirow[t]{2}{*}{ Catholic } & $0.20^{*}$ & $0.20^{*}$ & $0.20^{*}$ & $0.20^{*}$ & $0.19^{*}$ & $0.20^{*}$ & $0.21^{*}$ \\
\hline & $(0.08)$ & $(0.08)$ & $(0.08)$ & $(0.08)$ & $(0.08)$ & $(0.08)$ & $(0.08)$ \\
\hline \multirow[t]{2}{*}{ Muslim } & 0.06 & 0.06 & 0.06 & 0.06 & 0.05 & 0.05 & 0.05 \\
\hline & $(0.11)$ & $(0.11)$ & $(0.11)$ & $(0.11)$ & $(0.11)$ & $(0.11)$ & $(0.11)$ \\
\hline \multirow[t]{2}{*}{ Other } & -0.01 & -0.01 & -0.01 & -0.02 & -0.02 & -0.01 & -0.01 \\
\hline & $(0.14)$ & $(0.14)$ & $(0.14)$ & $(0.14)$ & $(0.14)$ & $(0.14)$ & $(0.14)$ \\
\hline Contextual level & ref. & ref. & ref. & ref. & ref. & ref. & ref. \\
\hline \multirow[t]{2}{*}{ East Germany } & 0.11 & 0.09 & 0.08 & 0.10 & $0.20^{*}$ & 0.12 & 0.08 \\
\hline & $(0.08)$ & $(0.08)$ & $(0.09)$ & $(0.08)$ & $(0.08)$ & $(0.08)$ & $(0.08)$ \\
\hline \multirow[t]{2}{*}{ Local Unemployment Rate } & -0.02 & -0.02 & -0.01 & -0.01 & -0.01 & $-0.02^{*}$ & -0.02 \\
\hline & $(0.01)$ & $(0.01)$ & $(0.01)$ & $(0.01)$ & $(0.01)$ & $(0.01)$ & $(0.01)$ \\
\hline \multirow[t]{2}{*}{ Population Density } & 0.05 & 0.04 & 0.04 & 0.04 & -0.02 & $0.06^{*}$ & $0.05^{*}$ \\
\hline & $(0.03)$ & $(0.02)$ & $(0.02)$ & $(0.03)$ & $(0.02)$ & $(0.03)$ & $(0.03)$ \\
\hline \multirow[t]{2}{*}{ Crime Rate } & $-2.67^{* *}$ & $-2.80^{* * *}$ & $-2.70^{* *}$ & $-2.73^{* *}$ & $-3.23^{* * *}$ & $-2.24^{*}$ & $-2.69^{* *}$ \\
\hline & $(0.80)$ & $(0.78)$ & $(0.82)$ & $(0.81)$ & $(0.76)$ & $(0.86)$ & $(0.82)$ \\
\hline \multirow[t]{2}{*}{ Constant } & $5.53^{* * *}$ & $5.54^{* * *}$ & $5.48^{* * *}$ & $5.49^{* * *}$ & $5.38^{* * *}$ & $5.53^{* * *}$ & $5.61^{* * *}$ \\
\hline & $(0.20)$ & $(0.20)$ & $(0.20)$ & $(0.20)$ & $(0.20)$ & $(0.20)$ & $(0.19)$ \\
\hline Observations & 7979 & 7979 & 7979 & 7979 & 7979 & 7979 & 7979 \\
\hline$R^{2}$ & 0.109 & 0.109 & 0.109 & 0.108 & 0.108 & 0.109 & 0.109 \\
\hline Adjusted $R^{2}$ & 0.107 & 0.107 & 0.107 & 0.106 & 0.106 & 0.107 & 0.107 \\
\hline
\end{tabular}


Table B.6: Results for the control variables of Table 3 (collective efficacy)

\begin{tabular}{|c|c|c|c|c|c|c|c|}
\hline & (1) & (2) & (3) & (4) & (5) & (6) & (7) \\
\hline Individual level & ref. & ref. & ref. & ref. & ref. & ref. & ref. \\
\hline \multirow[t]{2}{*}{ Age } & -0.00 & -0.00 & -0.00 & -0.00 & -0.00 & -0.00 & -0.00 \\
\hline & $(0.00)$ & $(0.00)$ & $(0.00)$ & $(0.00)$ & $(0.00)$ & $(0.00)$ & $(0.00)$ \\
\hline \multirow{3}{*}{$\begin{array}{l}\text { Education, referece: Low } \\
\text { Middle }\end{array}$} & ref. & ref. & ref. & ref. & ref. & ref. & ref. \\
\hline & 0.08 & 0.08 & 0.08 & 0.08 & 0.09 & 0.08 & 0.08 \\
\hline & $(0.12)$ & $(0.12)$ & $(0.12)$ & $(0.12)$ & $(0.12)$ & $(0.12)$ & $(0.12)$ \\
\hline \multirow[t]{2}{*}{ High } & 0.14 & 0.14 & 0.14 & 0.14 & 0.15 & 0.14 & 0.14 \\
\hline & $(0.13)$ & $(0.13)$ & $(0.13)$ & $(0.13)$ & $(0.13)$ & $(0.13)$ & $(0.13)$ \\
\hline \multirow[t]{2}{*}{ Employed } & $0.19^{* * *}$ & $0.19^{* * *}$ & $0.19^{* * *}$ & $0.19^{* * *}$ & $0.19^{* * *}$ & $0.19^{* * *}$ & $0.19^{* * *}$ \\
\hline & $(0.05)$ & $(0.05)$ & $(0.05)$ & $(0.05)$ & $(0.05)$ & $(0.05)$ & $(0.05)$ \\
\hline \multirow{2}{*}{ Years in the Nbh. } & $0.00^{*}$ & $0.00^{*}$ & $0.00^{*}$ & $0.00^{*}$ & $0.00^{*}$ & $0.00^{*}$ & $0.00^{*}$ \\
\hline & $(0.00)$ & $(0.00)$ & $(0.00)$ & $(0.00)$ & $(0.00)$ & $(0.00)$ & $(0.00)$ \\
\hline \multirow[t]{2}{*}{ Home Owner } & $0.81^{* * *}$ & $0.81^{* * *}$ & $0.81^{* * *}$ & $0.81^{* * *}$ & $0.81^{* * *}$ & $0.81^{* * *}$ & $0.80^{* * *}$ \\
\hline & $(0.08)$ & $(0.08)$ & $(0.08)$ & $(0.08)$ & $(0.08)$ & $(0.08)$ & $(0.08)$ \\
\hline \multirow[t]{2}{*}{ Female } & $0.24^{* * *}$ & $0.24^{* * *}$ & $0.24^{* * *}$ & $0.24^{* * *}$ & $0.24^{* * *}$ & $0.24^{* * *}$ & $0.24^{* * *}$ \\
\hline & $(0.06)$ & $(0.06)$ & $(0.06)$ & $(0.06)$ & $(0.06)$ & $(0.06)$ & $(0.06)$ \\
\hline \multirow[t]{2}{*}{ Immigrant origin } & -0.03 & -0.03 & -0.03 & -0.03 & -0.04 & -0.03 & -0.20 \\
\hline & $(0.09)$ & $(0.09)$ & $(0.09)$ & $(0.09)$ & $(0.09)$ & $(0.09)$ & $(0.14)$ \\
\hline \multirow[t]{2}{*}{ Married } & $0.37^{* * *}$ & $0.37^{* * *}$ & $0.37^{* * *}$ & $0.37^{* * *}$ & $0.36^{* * *}$ & $0.37^{* * *}$ & $0.37^{* * *}$ \\
\hline & $(0.05)$ & $(0.05)$ & $(0.05)$ & $(0.05)$ & $(0.05)$ & $(0.05)$ & $(0.05)$ \\
\hline \multirow{3}{*}{$\begin{array}{l}\text { Religion, reference: Atheist } \\
\text { Protestant }\end{array}$} & ref. & ref. & ref. & ref. & ref. & ref. & ref. \\
\hline & $0.36^{* * *}$ & $0.36^{* * *}$ & $0.36^{* * *}$ & $0.36^{* * *}$ & $0.36^{* * *}$ & $0.36^{* * *}$ & $0.36^{* * *}$ \\
\hline & $(0.09)$ & $(0.09)$ & $(0.09)$ & $(0.09)$ & $(0.09)$ & $(0.09)$ & $(0.09)$ \\
\hline \multirow[t]{2}{*}{ Catholic } & 0.14 & 0.14 & 0.14 & 0.14 & 0.13 & 0.14 & $0.14^{*}$ \\
\hline & $(0.07)$ & $(0.07)$ & $(0.07)$ & $(0.07)$ & $(0.07)$ & $(0.07)$ & $(0.07)$ \\
\hline \multirow[t]{2}{*}{ Muslim } & 0.09 & 0.09 & 0.09 & 0.09 & 0.09 & 0.09 & 0.09 \\
\hline & $(0.10)$ & $(0.10)$ & $(0.10)$ & $(0.10)$ & $(0.10)$ & $(0.10)$ & $(0.10)$ \\
\hline \multirow[t]{2}{*}{ Other } & -0.10 & -0.10 & -0.10 & -0.10 & -0.10 & -0.10 & -0.09 \\
\hline & $(0.15)$ & $(0.15)$ & $(0.15)$ & $(0.15)$ & $(0.15)$ & $(0.15)$ & $(0.16)$ \\
\hline Contextual level & ref. & ref. & ref. & ref. & ref. & ref. & ref. \\
\hline \multirow[t]{2}{*}{ East Germany } & 0.12 & 0.09 & 0.09 & 0.11 & 0.20 & 0.13 & 0.09 \\
\hline & $(0.10)$ & $(0.11)$ & $(0.11)$ & $(0.11)$ & $(0.10)$ & $(0.10)$ & $(0.10)$ \\
\hline \multirow[t]{2}{*}{ Local Unemployment Rate } & -0.01 & -0.01 & -0.01 & -0.01 & -0.01 & -0.02 & -0.01 \\
\hline & $(0.01)$ & $(0.01)$ & $(0.01)$ & $(0.01)$ & $(0.01)$ & $(0.01)$ & $(0.01)$ \\
\hline \multirow[t]{2}{*}{ Population Density } & -0.03 & -0.03 & -0.04 & -0.04 & $-0.10^{* * *}$ & -0.02 & -0.02 \\
\hline & $(0.03)$ & $(0.03)$ & $(0.03)$ & $(0.03)$ & $(0.02)$ & $(0.03)$ & $(0.03)$ \\
\hline \multirow[t]{2}{*}{ Crime Rate } & $-4.11^{* * *}$ & $-4.20^{* * *}$ & $-4.12^{* * *}$ & $-4.17^{* * *}$ & $-4.89^{* * *}$ & $-3.71^{* * *}$ & $-4.13^{* * *}$ \\
\hline & $(0.86)$ & $(0.85)$ & $(0.86)$ & $(0.88)$ & $(0.97)$ & $(0.92)$ & $(0.87)$ \\
\hline \multirow[t]{2}{*}{ Constant } & $5.87^{* * *}$ & $5.90^{* * *}$ & $5.83^{* * *}$ & $5.84^{* * *}$ & $5.78^{* * *}$ & $5.88^{* * *}$ & $5.96^{* * *}$ \\
\hline & $(0.19)$ & $(0.20)$ & $(0.19)$ & $(0.19)$ & $(0.19)$ & $(0.19)$ & $(0.19)$ \\
\hline Observations & 7979 & 7979 & 7979 & 7979 & 7979 & 7979 & 7979 \\
\hline$R^{2}$ & 0.074 & 0.074 & 0.074 & 0.074 & 0.073 & 0.074 & 0.074 \\
\hline Adjusted $R^{2}$ & 0.072 & 0.072 & 0.072 & 0.072 & 0.071 & 0.072 & 0.072 \\
\hline
\end{tabular}


859 Appendix C. Additional results 
Table C.7: Two indicators of social cohesion and the LSU index interacted with the share of persons of immigrant origin

\begin{tabular}{|c|c|c|}
\hline & $\begin{array}{l}(1) \\
\text { Trust in Neighbours }\end{array}$ & $\begin{array}{c}(2) \\
\text { Collective Efficacy }\end{array}$ \\
\hline Individual level & ref. & ref. \\
\hline Age & $\begin{array}{c}0.02^{* * *} \\
(0.00)\end{array}$ & $\begin{array}{l}-0.00 \\
(0.00)\end{array}$ \\
\hline Education, referece: Low & ref. & ref. \\
\hline Middle & $\begin{array}{c}0.18 \\
(0.10)\end{array}$ & $\begin{array}{c}0.09 \\
(0.12)\end{array}$ \\
\hline High & $\begin{array}{c}0.43^{* * *} \\
(0.11)\end{array}$ & $\begin{array}{c}0.14 \\
(0.13)\end{array}$ \\
\hline Employed & $\begin{array}{c}0.05 \\
(0.06)\end{array}$ & $\begin{array}{c}0.19^{* * * *} \\
(0.05)\end{array}$ \\
\hline Years in the Nbh. & $\begin{array}{c}0.01^{* * *} \\
(0.00)\end{array}$ & $\begin{array}{l}0.00^{*} \\
(0.00)\end{array}$ \\
\hline Home Owner & $\begin{array}{c}0.55^{* * *} \\
(0.05)\end{array}$ & $\begin{array}{c}0.81^{* * *} \\
(0.08)\end{array}$ \\
\hline Female & $\begin{array}{l}0.17^{* *} \\
(0.05)\end{array}$ & $\begin{array}{c}0.24^{* * *} \\
(0.06)\end{array}$ \\
\hline Immigrant origin & $\begin{array}{c}-0.38^{* * *} \\
(0.08)\end{array}$ & $\begin{array}{l}-0.02 \\
(0.09)\end{array}$ \\
\hline Married & $\begin{array}{c}0.39^{* * *} \\
(0.05)\end{array}$ & $\begin{array}{c}0.37^{* * *} \\
(0.05)\end{array}$ \\
\hline $\begin{array}{l}\text { Religion, reference: Atheist } \\
\text { Protestant }\end{array}$ & $\begin{array}{c}\text { ref. } \\
0.39^{* * *} \\
(0.07)\end{array}$ & $\begin{array}{c}\text { ref. } \\
0.36^{* * *} \\
(0.09)\end{array}$ \\
\hline Catholic & $\begin{array}{l}0.20^{*} \\
(0.08)\end{array}$ & $\begin{array}{l}0.14^{*} \\
(0.07)\end{array}$ \\
\hline Muslim & $\begin{array}{c}0.05 \\
(0.11)\end{array}$ & $\begin{array}{c}0.10 \\
(0.10)\end{array}$ \\
\hline Other & $\begin{array}{l}-0.02 \\
(0.14)\end{array}$ & $\begin{array}{l}-0.09 \\
(0.15)\end{array}$ \\
\hline Contextual level & ref. & ref. \\
\hline East Germany & $\begin{array}{c}0.06 \\
(0.08)\end{array}$ & $\begin{array}{c}0.08 \\
(0.10)\end{array}$ \\
\hline Local Unemployment Rate & $\begin{array}{l}-0.02^{*} \\
(0.01)\end{array}$ & $\begin{array}{l}-0.02 \\
(0.01)\end{array}$ \\
\hline Population Density & $\begin{array}{l}0.07^{*} \\
(0.03)\end{array}$ & $\begin{array}{l}-0.02 \\
(0.03)\end{array}$ \\
\hline Crime Rate & $\begin{array}{l}-2.08^{*} \\
(0.82)\end{array}$ & $\begin{array}{c}-3.87^{* * *} \\
(0.94)\end{array}$ \\
\hline $\begin{array}{l}\text { Indices } \\
\text { LSU }\end{array}$ & $\begin{array}{c}\text { ref. } \\
0.09 \\
(0.18)\end{array}$ & $\begin{array}{c}\text { ref. } \\
-0.15 \\
(0.25)\end{array}$ \\
\hline \%Immigrant origin & $\begin{array}{c}-0.02^{* * *} \\
(0.01)\end{array}$ & $\begin{array}{c}-0.02^{* *} \\
(0.01)\end{array}$ \\
\hline LSU*\%Immigrant origin & $\begin{array}{c}0.01 \\
(0.02)\end{array}$ & $\begin{array}{l}-0.00 \\
(0.02)\end{array}$ \\
\hline Constant & $\begin{array}{c}5.62^{* * *} \\
(0.19)\end{array}$ & $\begin{array}{c}5.98^{* * *} \\
(0.20)\end{array}$ \\
\hline Observations & 7979 & 7979 \\
\hline$R^{2}$ & 0.109 & 0.074 \\
\hline Adjusted $R^{2}$ & 0.107 & 0.072 \\
\hline
\end{tabular}


Table C.8: Trust in neighbours and competing, inflated diversity indices

\begin{tabular}{|c|c|c|c|c|c|c|}
\hline & (1) & $(2)$ & (3) & (4) & (5) & (6) \\
\hline Individual level & ref. & ref. & ref. & ref. & ref. & ref. \\
\hline Age & $\begin{array}{c}0.02^{* * *} \\
(0.00)\end{array}$ & $\begin{array}{c}0.02^{* * *} \\
(0.00)\end{array}$ & $\begin{array}{c}0.02^{* * *} \\
(0.00)\end{array}$ & $\begin{array}{c}0.02^{* * *} \\
(0.00)\end{array}$ & $\begin{array}{c}0.02^{* * *} \\
(0.00)\end{array}$ & $\begin{array}{c}0.02^{* * *} \\
(0.00)\end{array}$ \\
\hline $\begin{array}{l}\text { Education, referece: } \\
\text { Low }\end{array}$ & ref. & ref. & ref. & ref. & ref. & ref. \\
\hline Middle & $\begin{array}{c}0.17 \\
(0.10)\end{array}$ & $\begin{array}{c}0.17 \\
(0.10)\end{array}$ & $\begin{array}{c}0.17 \\
(0.10)\end{array}$ & $\begin{array}{c}0.17 \\
(0.10)\end{array}$ & $\begin{array}{c}0.17 \\
(0.10)\end{array}$ & $\begin{array}{c}0.17 \\
(0.10)\end{array}$ \\
\hline High & $\begin{array}{c}0.42^{* * *} \\
(0.12)\end{array}$ & $\begin{array}{c}0.42^{* * * *} \\
(0.12)\end{array}$ & $\begin{array}{c}0.42^{* * *} \\
(0.12)\end{array}$ & $\begin{array}{c}0.41^{* * *} \\
(0.12)\end{array}$ & $\begin{array}{c}0.41^{* * *} \\
(0.12)\end{array}$ & $\begin{array}{c}0.42^{* * *} \\
(0.12)\end{array}$ \\
\hline Employed & $\begin{array}{c}0.05 \\
(0.06)\end{array}$ & $\begin{array}{c}0.05 \\
(0.06)\end{array}$ & $\begin{array}{c}0.05 \\
(0.06)\end{array}$ & $\begin{array}{c}0.05 \\
(0.06)\end{array}$ & $\begin{array}{c}0.05 \\
(0.06)\end{array}$ & $\begin{array}{c}0.05 \\
(0.06)\end{array}$ \\
\hline Years in the Nbh. & $\begin{array}{c}0.01^{* * *} \\
(0.00)\end{array}$ & $\begin{array}{c}0.01^{* * *} \\
(0.00)\end{array}$ & $\begin{array}{c}0.01^{* * *} \\
(0.00)\end{array}$ & $\begin{array}{c}0.01^{* * *} \\
(0.00)\end{array}$ & $\begin{array}{c}0.01^{* * *} \\
(0.00)\end{array}$ & $\begin{array}{c}0.01^{* * *} \\
(0.00)\end{array}$ \\
\hline Home Owner & $\begin{array}{c}0.55^{* * *} \\
(0.05)\end{array}$ & $\begin{array}{c}0.55^{* * *} \\
(0.05)\end{array}$ & $\begin{array}{c}0.55^{* * *} \\
(0.05)\end{array}$ & $\begin{array}{c}0.55^{* * *} \\
(0.05)\end{array}$ & $\begin{array}{c}0.55^{* * *} \\
(0.05)\end{array}$ & $\begin{array}{c}0.55^{* * *} \\
(0.05)\end{array}$ \\
\hline Female & $\begin{array}{c}0.16^{* *} \\
(0.05)\end{array}$ & $\begin{array}{r}0.16^{* *} \\
(0.05)\end{array}$ & $\begin{array}{l}0.16^{* *} \\
(0.05)\end{array}$ & $\begin{array}{l}0.16^{* *} \\
(0.05)\end{array}$ & $\begin{array}{l}0.16^{* *} \\
(0.05)\end{array}$ & $\begin{array}{l}0.16^{* *} \\
(0.05)\end{array}$ \\
\hline Immigrant origin & $\begin{array}{c}-0.38^{* * *} \\
(0.08)\end{array}$ & $\begin{array}{c}-0.39^{* * *} \\
(0.08)\end{array}$ & $\begin{array}{c}-0.38^{* * *} \\
(0.08)\end{array}$ & $\begin{array}{c}-0.38^{* * *} \\
(0.08)\end{array}$ & $\begin{array}{c}-0.38^{* * *} \\
(0.08)\end{array}$ & $\begin{array}{c}-0.60^{* * *} \\
(0.17)\end{array}$ \\
\hline Married & $\begin{array}{c}0.38^{* * *} \\
(0.05)\end{array}$ & $\begin{array}{c}0.38^{* * *} \\
(0.05)\end{array}$ & $\begin{array}{c}0.38^{* * *} \\
(0.05)\end{array}$ & $\begin{array}{c}0.38^{* * *} \\
(0.05)\end{array}$ & $\begin{array}{c}0.38^{* * *} \\
(0.05)\end{array}$ & $\begin{array}{c}0.38^{* * *} \\
(0.05)\end{array}$ \\
\hline $\begin{array}{l}\text { Religion, reference: } \\
\text { Atheist }\end{array}$ & ref. & ref. & ref. & ref. & ref. & ref. \\
\hline Protestant & $\begin{array}{c}0.41^{* * *} \\
(0.07)\end{array}$ & $\begin{array}{c}0.41^{* * *} \\
(0.07)\end{array}$ & $\begin{array}{c}0.41^{* * *} \\
(0.07)\end{array}$ & $\begin{array}{c}0.41^{* * *} \\
(0.07)\end{array}$ & $\begin{array}{c}0.41^{* * *} \\
(0.07)\end{array}$ & $\begin{array}{c}0.41^{* * *} \\
(0.07)\end{array}$ \\
\hline Catholic & $\begin{array}{l}0.21^{*} \\
(0.09)\end{array}$ & $\begin{array}{l}0.21^{*} \\
(0.09)\end{array}$ & $\begin{array}{l}0.20^{*} \\
(0.09)\end{array}$ & $\begin{array}{l}0.21^{*} \\
(0.09)\end{array}$ & $\begin{array}{l}0.21^{*} \\
(0.09)\end{array}$ & $\begin{array}{l}0.21^{*} \\
(0.09)\end{array}$ \\
\hline Muslim & $\begin{array}{c}0.07 \\
(0.11)\end{array}$ & $\begin{array}{c}0.07 \\
(0.11)\end{array}$ & $\begin{array}{c}0.07 \\
(0.11)\end{array}$ & $\begin{array}{c}0.07 \\
(0.11)\end{array}$ & $\begin{array}{c}0.07 \\
(0.11)\end{array}$ & $\begin{array}{c}0.06 \\
(0.11)\end{array}$ \\
\hline Other & $\begin{array}{l}0.00 \\
(0.15)\end{array}$ & $\begin{array}{c}0.00 \\
(0.15)\end{array}$ & $\begin{array}{l}0.00 \\
(0.15)\end{array}$ & $\begin{array}{c}0.00 \\
(0.15)\end{array}$ & $\begin{array}{c}0.00 \\
(0.15)\end{array}$ & $\begin{array}{c}0.00 \\
(0.15)\end{array}$ \\
\hline Contextual level & ref. & ref. & ref. & ref. & ref. & ref. \\
\hline East Germany & $\begin{array}{c}0.06 \\
(0.09)\end{array}$ & $\begin{array}{c}0.04 \\
(0.10)\end{array}$ & $\begin{array}{c}0.05 \\
(0.10)\end{array}$ & $\begin{array}{c}0.06 \\
(0.09)\end{array}$ & $\begin{array}{c}0.07 \\
(0.09)\end{array}$ & $\begin{array}{c}0.03 \\
(0.09)\end{array}$ \\
\hline $\begin{array}{l}\text { Local Unemployment } \\
\text { Rate }\end{array}$ & -0.02 & -0.01 & -0.02 & -0.01 & -0.02 & -0.02 \\
\hline & $(0.01)$ & $(0.01)$ & $(0.01)$ & $(0.01)$ & $(0.01)$ & $(0.01)$ \\
\hline Population Density & $\begin{array}{c}0.05 \\
(0.03)\end{array}$ & $\begin{array}{c}0.03 \\
(0.02)\end{array}$ & $\begin{array}{c}0.04 \\
(0.03)\end{array}$ & $\begin{array}{c}0.03 \\
(0.02)\end{array}$ & $\begin{array}{l}0.05^{*} \\
(0.03)\end{array}$ & $\begin{array}{l}0.05^{*} \\
(0.03)\end{array}$ \\
\hline Crime Rate & $\begin{array}{c}-2.36^{* *} \\
(0.86)\end{array}$ & $\begin{array}{c}-2.93^{* * *} \\
(0.77)\end{array}$ & $\begin{array}{l}-1.87 \\
(1.04)\end{array}$ & $\begin{array}{c}-2.97^{* * *} \\
(0.77)\end{array}$ & $\begin{array}{l}-2.32^{*} \\
(0.87)\end{array}$ & $\begin{array}{c}-2.42^{* *} \\
(0.88)\end{array}$ \\
\hline $\begin{array}{l}\text { Indices } \\
\mathrm{HHI}\end{array}$ & $\begin{array}{c}\text { ref. } \\
-1.11^{* *} \\
(0.35)\end{array}$ & & & & & $\begin{array}{c}\text { ref. } \\
-1.42^{* * *} \\
(0.34)\end{array}$ \\
\hline $\mathrm{EP}$ & & $\begin{array}{l}-0.75^{*} \\
(0.31)\end{array}$ & & & & \\
\hline CED & & & $\begin{array}{l}-2.19^{*} \\
(0.82)\end{array}$ & & & \\
\hline EGI & & & & $\begin{array}{c}-7.75^{* *} \\
(2.88)\end{array}$ & & \\
\hline \%Immigrant origin & & & & & $\begin{array}{c}-0.02^{* *} \\
(0.01)\end{array}$ & \\
\hline $\begin{array}{l}\text { Interactions } \\
\mathrm{HHI}^{*} \text { Immigrant Origin }\end{array}$ & & & & & & $\begin{array}{c}\text { ref. } \\
0.71 \\
(0.51)\end{array}$ \\
\hline Constant & $\begin{array}{c}5.63^{* * *} \\
(0.20)\end{array}$ & $\begin{array}{c}5.63^{* * *} \\
(0.21)\end{array}$ & $\begin{array}{c}5.59^{* * *} \\
(0.20)\end{array}$ & $\begin{array}{c}5.54^{* * *} \\
(0.20)\end{array}$ & $\begin{array}{c}5.60^{* * *} \\
(0.19)\end{array}$ & $\begin{array}{c}5.72^{* * *} \\
(0.19)\end{array}$ \\
\hline Observations & 7979 & 7979 & 7979 & 7979 & 7979 & 7979 \\
\hline$R^{2}$ & 0.109 & 0.109 & 0.109 & 0.109 & 0.109 & 0.109 \\
\hline Adjusted $R^{2}$ & 0.107 & 0.107 & 0.107 & 0.107 & 0.107 & 0.107 \\
\hline \multicolumn{7}{|c|}{$\begin{array}{l}\text { Cluster-robust standard errors in parentheses; }{ }^{*} p<0.05,{ }^{* *} p<0.01 \\
H H I: \text { Hirschman-Herfindahl Index } \\
E P: \text { Ethnic polarization index } \\
C E D: \text { Culturally weighted ethnic diversity index } \\
\text { EGI: Economic group based indequality index } \\
L S U: \text { Average regional migrant host-country language skills and usage }\end{array}$} \\
\hline
\end{tabular}


Table C.9: Collective efficacy and competing, inflated diversity indices

\begin{tabular}{|c|c|c|c|c|c|c|}
\hline & (1) & $(2)$ & (3) & (4) & (5) & (6) \\
\hline \multirow{3}{*}{$\begin{array}{l}\text { Individual level } \\
\text { Age }\end{array}$} & ref. & ref. & ref. & ref. & ref. & ref. \\
\hline & -0.00 & -0.00 & -0.00 & -0.00 & -0.00 & -0.00 \\
\hline & $(0.00)$ & $(0.00)$ & $(0.00)$ & $(0.00)$ & $(0.00)$ & $(0.00)$ \\
\hline $\begin{array}{l}\text { Education, referece: } \\
\text { Low }\end{array}$ & ref. & ref. & ref. & ref. & ref. & ref. \\
\hline \multirow[t]{2}{*}{ Middle } & 0.10 & 0.11 & 0.11 & 0.10 & 0.10 & 0.10 \\
\hline & $(0.11)$ & $(0.11)$ & $(0.11)$ & $(0.11)$ & $(0.11)$ & $(0.11)$ \\
\hline \multirow[t]{2}{*}{ High } & 0.17 & 0.17 & 0.17 & 0.17 & 0.17 & 0.17 \\
\hline & $(0.13)$ & $(0.13)$ & $(0.13)$ & $(0.13)$ & $(0.13)$ & $(0.13)$ \\
\hline \multirow[t]{2}{*}{ Employed } & $0.17^{* *}$ & $0.17^{* *}$ & $0.17^{* *}$ & $0.17^{* *}$ & $0.17^{* *}$ & $0.17^{* *}$ \\
\hline & $(0.05)$ & $(0.05)$ & $(0.05)$ & $(0.05)$ & $(0.05)$ & $(0.05)$ \\
\hline \multirow[t]{2}{*}{ Years in the Nbh. } & 0.00 & 0.00 & 0.00 & 0.00 & 0.00 & 0.00 \\
\hline & $(0.00)$ & $(0.00)$ & $(0.00)$ & $(0.00)$ & $(0.00)$ & $(0.00)$ \\
\hline Home Owner & $0.80^{* * *}$ & $0.80^{* * *}$ & $0.80^{* * *}$ & $0.80^{* * *}$ & $0.80^{* * *}$ & $0.80^{* * *}$ \\
\hline \multirow{2}{*}{ Female } & $\begin{array}{c}(0.08) \\
0.24^{* * *}\end{array}$ & $\begin{array}{c}(0.08) \\
0.24^{* * *}\end{array}$ & $\begin{array}{c}(0.08) \\
0.24^{* * *}\end{array}$ & $\begin{array}{c}(0.08) \\
0.24^{* * *}\end{array}$ & $\begin{array}{c}(0.08) \\
0.24^{* * *}\end{array}$ & $\begin{array}{c}(0.08) \\
0.23^{* * *}\end{array}$ \\
\hline & $(0.05)$ & $(0.05)$ & $(0.05)$ & $(0.05)$ & $(0.05)$ & $(0.05)$ \\
\hline \multirow[t]{2}{*}{ Immigrant origin } & -0.04 & -0.04 & -0.04 & -0.04 & -0.04 & -0.23 \\
\hline & $(0.09)$ & $(0.09)$ & $(0.09)$ & $(0.09)$ & $(0.09)$ & $(0.17)$ \\
\hline Married & $0.37^{* * *}$ & $0.37^{* * *}$ & $0.37^{* * *}$ & $0.37^{* * *}$ & $0.37^{* * *}$ & $0.37^{* * *}$ \\
\hline reference: & $\begin{array}{l}(0.06) \\
\text { ref. }\end{array}$ & $\begin{array}{l}(0.06) \\
\text { ref. }\end{array}$ & $\begin{array}{l}\text { (0.06) } \\
\text { ref. }\end{array}$ & $\begin{array}{l}\text { (0.06) } \\
\text { ref. }\end{array}$ & $\begin{array}{l}(0.06) \\
\text { ref. }\end{array}$ & $\begin{array}{l}(0.06) \\
\text { ref. }\end{array}$ \\
\hline \multicolumn{7}{|l|}{ Atheist } \\
\hline Protestant & $\begin{array}{c}0.36^{* * *} \\
(0.09)\end{array}$ & $\begin{array}{c}0.36^{* * *} \\
(0.09)\end{array}$ & $\begin{array}{c}0.36^{* * *} \\
(0.09)\end{array}$ & $\begin{array}{c}0.37^{* * *} \\
(0.09)\end{array}$ & $\begin{array}{c}0.36^{* * *} \\
(0.09)\end{array}$ & $\begin{array}{c}0.36^{* * *} \\
(0.09)\end{array}$ \\
\hline \multirow[t]{2}{*}{ Catholic } & $0.15^{*}$ & $0.15^{*}$ & $0.14^{*}$ & $0.14^{*}$ & $0.15^{*}$ & $0.15^{*}$ \\
\hline & $(0.07)$ & $(0.07)$ & $(0.07)$ & $(0.07)$ & $(0.07)$ & $(0.07)$ \\
\hline \multirow[t]{2}{*}{ Muslim } & 0.11 & 0.12 & 0.11 & 0.11 & 0.11 & 0.11 \\
\hline & $(0.10)$ & $(0.10)$ & $(0.10)$ & $(0.10)$ & $(0.10)$ & $(0.10)$ \\
\hline \multirow[t]{2}{*}{ Other } & -0.07 & -0.07 & -0.07 & -0.07 & -0.07 & -0.07 \\
\hline & $(0.16)$ & $(0.16)$ & $(0.16)$ & $(0.16)$ & $(0.16)$ & $(0.16)$ \\
\hline Contextual level & ref. & ref. & ref. & ref. & ref. & ref. \\
\hline \multirow[t]{2}{*}{ East Germany } & 0.06 & -0.01 & 0.03 & 0.06 & 0.08 & 0.03 \\
\hline & $(0.11)$ & $(0.12)$ & $(0.11)$ & $(0.11)$ & $(0.10)$ & $(0.10)$ \\
\hline Local Unemployment & -0.01 & -0.00 & -0.01 & -0.00 & -0.02 & -0.01 \\
\hline & $(0.01)$ & $(0.01)$ & $(0.01)$ & $(0.01)$ & $(0.01)$ & $(0.01)$ \\
\hline Population Density & -0.02 & -0.04 & -0.02 & -0.05 & -0.02 & -0.02 \\
\hline & $(0.03)$ & $(0.03)$ & $(0.03)$ & $(0.03)$ & $(0.03)$ & $(0.03)$ \\
\hline Crime Rate & $-3.65^{* * *}$ & $-4.16^{* * *}$ & $-2.95^{*}$ & $-4.31^{* * *}$ & $-3.65^{* * *}$ & $-3.70^{* * *}$ \\
\hline & $(0.98)$ & $(0.97)$ & $(1.19)$ & $(0.95)$ & $(0.97)$ & $(0.98)$ \\
\hline Indices & ref. & & & & & ref. \\
\hline $\mathrm{HHI}$ & $\begin{array}{l}-1.18^{* * *} \\
(0.31)\end{array}$ & & & & & $\begin{array}{c}-1.46^{* * *} \\
(0.34)\end{array}$ \\
\hline EP & & $-1.00^{* * *}$ & & & & \\
\hline & & $(0.29)$ & & & & \\
\hline CED & & & $\begin{array}{c}-2.61^{* *} \\
(0.79)\end{array}$ & & & \\
\hline EGI & & & & $\begin{array}{c}-8.20^{* *} \\
(2.69)\end{array}$ & & \\
\hline \%Immigrant origin & & & & & $-0.02^{* * *}$ & \\
\hline & & & & & $(0.00)$ & \\
\hline Interactions & & & & & & ref. \\
\hline HHI*Immigrant Origin & & & & & & 0.63 \\
\hline & & & & & & $(0.46)$ \\
\hline Constant & $6.00^{* * *}$ & $6.07^{* * *}$ & $5.98^{* * *}$ & $5.91^{* * *}$ & $5.96^{* * *}$ & $6.09^{* * *}$ \\
\hline & $(0.19)$ & $(0.21)$ & $(0.20)$ & $(0.19)$ & $(0.19)$ & $(0.20)$ \\
\hline Observations & 7979 & 7979 & 7979 & 7979 & 7979 & 7979 \\
\hline$R^{2}$ & 0.074 & 0.074 & 0.074 & 0.073 & 0.074 & 0.074 \\
\hline Adjusted $R^{2}$ & 0.072 & 0.071 & 0.072 & 0.071 & 0.072 & 0.072 \\
\hline Cluster-robust standar & rs in $\mathrm{p}$ & theses; & $<0.05$ & $p<0.0$ & & \\
\hline & & & & & & \\
\hline EP: Ethnic polarization & dex & & & & & \\
\hline$C E D$ : Culturally weight & ethnic $\mathrm{d}$ & 16y 111 & & & & \\
\hline EGI: Economic group b & indeq & index & & & & \\
\hline . & & & & & & \\
\hline
\end{tabular}

